NBER WORKING PAPER SERIES

\title{
ECONOMIC IMPACTS OF UNIONIZATION \\ ON PRIVATE SECTOR EMPLOYERS: 1984-2001
}

\author{
John DiNardo \\ David S. Lee \\ Working Paper 10598 \\ http://www.nber.org/papers/w10598
NATIONAL BUREAU OF ECONOMIC RESEARCH
1050 Massachusetts Avenue
Cambridge, MA 02138
June 2004

Matthew Butler and Francisco Martorell provided outstanding research assistance. We would like to thank David Card, Robert J. LaLonde, Larry Katz, Enrico Moretti, Morris Kleiner, for helpful discussions and Hank Farber for providing election data. We would also like to thank seminar participants at the Bureau of Labor Statistics, the Federal Reserve Bank of Chicago, and the NBER Labor Economics Summer Institute, and the University of Michigan Labor Workshop for comments on an earlier paper, Ritch Milby at the California Census Data Center, Andrew Hildreth, and Thomas Kochan. The research in this paper was conducted while one of the authors was a Census Bureau research associate at the Berkeley California Census Research Data Center. Research results and conclusions expressed are those of the authors and do not necessarily indicate concurrence by the Bureau of the Census, National Labor Relations Board, the Federal Mediation and Conciliation Service, or the Institute for Labor and Employment. The results in this paper have been screened to ensure that no confidential data are revealed. The views expressed herein are those of the author(s) and not necessarily those of the National Bureau of Economic Research.

C2004 by John DiNardo and David S. Lee. All rights reserved. Short sections of text, not to exceed two paragraphs, may be quoted without explicit permission provided that full credit, including $@$ notice, is given to the source. 
Economic Impacts of Unionization on Private Sector Employers: 1984-2001

John DiNardo and David S. Lee

NBER Working Paper No. 10598

June 2004

JEL No. J0, J2, J3, J5, C1, C5

\section{$\underline{\text { ABSTRACT }}$}

Economic impacts of unionization on employers are difficult to estimate in the absence of large, representative data on establishments with union status information. Estimates are also confounded by selection bias, because unions could organize at highly profitable enterprises that are more likely to grow and pay higher wages. Using multiple establishment-level data sets that represent establishments that faced organizing drives in the U.S. during 1984-1999, this paper uses a regression discontinuity design to estimate the impact of unionization on business survival, employment, output, productivity, and wages. Essentially, outcomes for employers where unions barely won the election (e.g. by one vote) are compared to those where the unions barely lost. The analysis finds small impacts on all outcomes that we examine; estimates for wages are close to zero. The evidence suggests that - at least in recent decades - the legal mandate that requires the employer to bargain with a certified union has had little economic impact on employers, because unions have been somewhat unsuccessful at securing significant wage gains.

John Dinardo

440 Lorch Hall

Ford School of Public Policy

University of Michigan

Ann Arbor, MI 48109-1220

and NBER

jdinardo@umich.edu

David S. Lee

Department of Economics

549 Evans Hall, \#3880

Berkeley, CA 94720-3880

and NBER

dslee@econ.berkeley.edu 


\section{Introduction}

It is widely understood that unions impose costs to employers: the most important way is by raising members' wages. ${ }^{1}$ They can also impose other costs on employers - by limiting discretion in hiring and firing, for example, and altering the structure of pay across skill groups. These constraints can lead employers to reduce employment, output, or most dramatically, to cease operation all together. ${ }^{2}$ Indeed, these effects are often directly acknowledged by employers and employees alike. During union organizing drives, for example, firms routinely threaten to close a plant if the union drive is successful (Bronfenbrenner 1994), and employees seem to take these threats seriously: the risk of plant closure is cited as the leading cause of union withdrawal from organizing attempts. ${ }^{3}$

Are the costs of unionization to employers large or small? Today, in the United States, arguments can be made for either case. On the one hand, recent data show little change in one extensively studied measure of union power - the union wage premium: union workers receive a wage premium of 15 percent or higher over demographically similar non-union workers. To the extent that employers are sensitive to the price of labor, this may lead to large reductions in employment. ${ }^{4}$ On the other hand, there is a broad consensus that in the past three decades, union power in the U.S. has been on the decline. There has been a decrease in union membership, and new organizing activity, ${ }^{5}$ high levels of managerial opposition, and increased use of permanent replacement workers. ${ }^{6}$ During the 1980 s, prominent unions were accepting wage cuts, facing the pressures of the opening of international competition.

At least two important challenges hinder credible measurement of the causal impacts of unionization on employers. One limiting factor is the absence of large, representative data sets that track establish-

\footnotetext{
1 Of particular note are H. Gregg Lewis's seminal surveys on union wage gaps see Lewis (1963), Lewis (1986a), and Lewis (1986b). For a more recent examination, see Blanchflower \& Bryson (2003).

2 See for example, Abowd (1989), Ruback \& Zimmerman (1984), Freeman \& Medoff (1984), and Hirsch \& Schumacher (1998). For a recent survey and critique, see Hirsch (2004).

3 See Commission for Labor Cooperation (1997). The Commission for Labor Cooperation was a tri-national organization created under the North American Agreement on Labor Cooperation ("NAALC") in response to labor issues related to the North American Free Trade Agreement. The report issued by the Commission - which was prompted by a Mexican request that followed a plant closure in the U.S. during a unionization drive - wrote that "the findings of this report suggest that plant closings and threats of plant closing can have adverse effects on workers freedom of association."

4 See Mankiw (2004) for a textbook example of the argument. Recently, in cross-country analysis Nickell \& Layard (1999) report that a change from 25 to over 70 percent of the workers covered by collective bargaining is associated with a doubling of the unemployment rate. Lalonde, Marschke \& Troske (1996), using a "difference-in-difference" approach with LRD data, find successful organization is associated with significant declines in subsequent employment and output.

5 See LaLonde \& Meltzer (1991) and Farber (2001) for example.

6 Olson (1998), for example, finds that in all industries excluding construction, the use of striker replacements (as a fraction of strikes) were as high or much higher during the period 1985-1988 than they were during the (pre-Wagner Act) periods of 1901-11 and $1921-6$.
} 
ments over time that also provide information on union status. ${ }^{7}$ A second important concern is the fact that unionization is non-random. Depending on the correlation between factors associated with unionization and those associated with employment, output, and productivity, the observed correlation between union status and employer outcomes may overstate or understate the true effects of unions. Two competing phenomena may induce opposite selectivity biases. On the one hand, unions may tend to organize at highly successful enterprises that are more likely to survive and grow. On the other, a union organizing drive may be more likely to succeed when a firm is poorly managed, or has faced recent difficulties.

In this paper, we present quasi-experimental evidence on the causal effect of unionization on employer business failures/dislocations, employment, output, productivity, and wages, using two large databases representative of U.S. establishments at risk of being unionized. Our analysis is based on the fact that most new unionization occurs as a result of a secret ballot election. By law, if a majority of workers vote in favor of the union, the law requires the management to bargain "in good faith" with the recognized union. This process creates a natural set of comparisons between establishments that faced elections where the union barely won (say, by one vote) and those that faced elections where the union barely lost (by one vote). As in other regression- discontinuity designs, the comparison between near winners and near losers potentially eliminates any confounding selection and omitted variable biases, and allows us to devise credible and transparent estimates of the effect of unions on employer outcomes. ${ }^{8}$

We report several findings from analyzing data that spans the 1984-2001 period, and combines information on elections from the National Labor Relations Board (NLRB), on contract expirations from the Federal Mediation and Conciliation Service (FMCS), on subsequent business survival, employment, and output from a commercial database based on telephone listings (InfoUSA), as well as on employment, wages, output, and productivity in the manufacturing sector from the U.S. Census Bureau's Longitudinal Research Database (LRD).

We first document that the outcome of an NLRB election has a substantial, binding impact on the

\footnotetext{
7 This has led researchers to use creative data collection methods to examine these questions. For example, Freeman \& Kleiner (1990) conducted on-site interviews of 364 establishments that experienced representation elections in the Boston and Kansas City NLRB districts. Bronars \& Deere (1993) construct a dataset of NLRB elections to COMPUSTAT data to construct a panel of 85 firms over a 20-year period. Freeman \& Kleiner (1999) also use COMPUSTAT to construct a sample of 319 firms. Lalonde et al. (1996) match NLRB representation elections to a subset of manufacturing establishments that are continuously operating in the LRD to create samples with 500 to about 1100 observations.

8 Regression discontinuity designs are described in Thistlethwaite \& Campbell (1960) and Campbell (1969), and formally examined as an identification strategy recently in Hahn, van der Klaauw \& Todd (2001).
} 
collective bargaining process, even among close elections. Where they barely win the election, unions are able to maintain their legal recognition over long time horizons; where they barely lose, there is little evidence of subsequent attempts to organize the workplace. Furthermore, unions who barely win have as good a chance of securing a collective bargaining agreement with the employer as those who win the elections by wide margins. And, as expected, unions who barely lose an election have little chance of ever signing such an agreement. These facts show that - statistically speaking - employers face a minimal risk of ever entering collective bargaining negotiations after a union loses a closely-contested election.

This legally-mandated shift in the bargaining position of the workers, however, does not lead to significant impacts on a number of employer outcomes. First, union effects on business survival are small - on the order of -.01 to -.02 on a mean survival rate of .40 over an average of 8 years. Second, point estimates of the union impacts on employment, output, and productivity, are statistically significant; in the manufacturing sector, they range between -3 and 3 percent for production hours, between -4 and 4 percent for output, and between -2 and 0 percent for output per worker, over 1- to 15-year horizons.

One interpretation of our results is that the true effects are moderately sized (e.g. -6 or -7 percent for employment) but cannot be detected by our research design, due to sampling variability in our estimates. An alternative interpretation is that the effects are truly small (e.g. -2 or -3 percent). We favor the latter interpretation for the following reason: our estimates of union wage impacts are small - centered around zero - with enough precision to rule out a 2 percent wage increase for up to seven years after the election. This implies - provided that wage and employment outcomes remain on the employer's labor demand schedule - the impacts on employment are likely to be small, even assuming relatively large labor demand elasticities.

We also explore whether the small wage effects is an artifact of union "threat effects" - whereby employers raise wages to avoid the threat of future unionization. We do so by complementing our regressiondiscontinuity analysis with an "event-study" analysis that assesses whether wages rise in response to an election, even if the union eventually loses. Point estimates are small (between 0 and 2 percent) and statistically insignificant, ruling out a 3 percent "union threat" effect, 3 years after the election.

Based on the evidence, we conclude that - at least in recent decades in the United States - the legal mandate that requires the employer to bargain with a certified union has had little economic impact 
on employers, because unions have been somewhat unsuccessful at securing significant wage gains through collective bargaining.

The small wage effects that we estimate may appear to be at odds with an enormous literature that has documented substantial union wage premiums. The differing results, however, may be explained by some important differences - other than in research design - in the nature of the data used. First, the modern union wage premium literature typically examines individual-level household survey data, rather than establishment-level data. Freeman \& Kleiner (1990) argue that the latter is more appropriate for directly addressing the direct impacts of a workplace becoming unionized. ${ }^{9}$ Indeed, other establishmentlevel analyses find small or statistically undetectable wage effects (Freeman \& Kleiner (1990); Lalonde et al. (1996)). Second, the data contains information on recent unionization (within the past 20 years), while most worker-level data sets possess little information on when the union was formed; estimates derived from those data naturally cannot isolate wage impacts that result from unionization that occurred in recent decades. As noted in Freeman \& Kleiner (1990), existing wage differences between union and non-union workers today average the effects of unions of previous periods and the effects of unionization that occurs today.

Our results may also appear to be at odds with the standard "textbook" treatment of the neoclassical theory of union impacts, which emphasizes the notion of a union as an effective "monopoly" on labor services. There is, however, an older tradition in economics that argues - on a purely theoretical level - that most trade unions are unsuccessful monopolies. Indeed, in his essay, "The Impact of the Union," Milton Friedman (1950) argued that the ability of unions to raise wage rates at that time was somewhat exaggerated, because most unions could not overcome market forces that would tend to keep wages aligned with competitive rates. In a published exchange with Paul Samuelson, Friedman explains his reasoning: "I think if [UAW leader Walter] Reuther were to disregard [pressures to moderate wage demands] and if he were to seek - and for the moment let us suppose he is temporarily successful - very radically raised wages, and if that had the effect of grossly reducing employment within the automobile industry you would find opposition building up that would break the union down. Knowing that in advance and being as smart as

\footnotetext{
9 "While it is common to think of selectivity bias in estimating the union wage effect of the difference between the union (and nonunion) sample and the differential that would result from random organization of a set of workers or establishments, we do not believe that is the most useful way to express the problem. What is relevant is not what unionization would do to a randomly chosen establishment but rather what it would do to establishments with a reasonable chance of being unionized - to firms close the margin of being unionized than to the average nonunion establishment."
} 
you and I, he would avoid such action."

The paper is organized as follows. Section 2 provides some background on the union recognition process and the industrial relations climate in the U.S. in recent decades. Section 3 describes different notions of the causal impact of unionization, the regression-discontinuity design for estimating direct impacts of unionization, as well as the identification strategy for assessing indirect, "union threat" effects. We describe the various data sets in Section 4, present the results in Section 5, and discuss the findings in relation to the existing literature in Section 6. Section 7 concludes.

\section{The Union Recognition Process and the Industrial Relations Climate}

In this section, we provide some background on 1) how workers are "typically" unionized, 2) how examining representation elections is helpful for analyzing union impacts on employers, and 3) why the effects of unions today may differ from those in earlier decades.

In the United States, the effects of unions must be discussed in the context of the rights and protections that the law - as specified in the National Labor Relations Act (NLRA) - provides to unionized workers. For example, any group of workers could ignore the provisions of the NLRA, simply announce their membership in a union, and attempt to bargain "collectively" with an employer. In the current legal environment, the employer would not be required to bargain in good faith with such an entity and would face virtually no legal impediment to replacing such workers. By contrast, if a group of workers gains legal recognition as provided for by the NLRA, they are legally protected from being fired for association with a union and can only be "replaced" under specified conditions; most importantly, the law dictates that the employer bargain with the union "in good faith".

How is legal recognition of a union gained in the United States? There is no single path to an National Labor Relations Board (NLRB) election and eventual recognition of the union by the employer, but here is a prototypical scenario:

1. A group of workers decide to try to form a union. These workers contact a labor union and ask for assistance in beginning an organizing drive.

2. In collaboration with the union, the employees begin a "card drive." The purpose of the card drive is to be able to petition the NLRB to hold an election. Unions generally seek to get cards from at least 50 percent of the workers in the 6 month period of time usually allowed (although only $30 \%$ is legally required to be granted an election by the NLRB.)

3. After the cards have been submitted, the NLRB makes a ruling on whether the people the union seeks to 
represent have a "community of interest", a coherent group for the purposes of bargaining. The NLRB makes a determination of which categories of employees fall within the union's "bargaining unit." Often the parties will differ on the appropriate bargaining unit - employers generally prefer larger and more heterogeneous groupings than do unions.

4. Next, the NLRB holds an election at the work site (with exceptions to account for such things as the vagaries of employment seasonality). A simple majority (50 percent plus 1 vote) for one union is required to win.

5. Within 7 days after the final tally of the ballots, parties can file objections to how the election was conducted. With sufficient evidence that the election was not carried out properly, the NLRB can rule to invalidate the outcome of an election, and conduct another one thereafter. Specific ballots cannot be challenged after the voting is completed.

6. If after this, a union still has a simple majority, then the union is certified as the exclusive bargaining agent for the unit, and the employer is obligated to negotiate "in good faith" with that union.

In practice, employers are generally known to resist organizing drives. With data on firms who

faced NLRB elections in the early 1990s, Bronfenbrenner (1994) documents that most employers used

multiple tactics to delay or deny a collective bargaining agreement. Among the most common are

1. "Captive meetings". While employers are prohibited from directly firing workers participating in lawful union activity, at captive meetings employers are allowed to inform workers of the possible (dire) consequences of unionization, including making the business more susceptible to closure.

2. Firing union activists. While legally prohibited, the penalty imposed on employers, if found guilty, is generally quite minor - reinstatement with back pay. Indeed, the costs have been perceived as so minor that Freeman (1985) observes that the notices that firms are required to post when they engage in illegal firing are referred to as "hunting licenses."

3. Hire a "management consultant" who advises employers on a variety of tactics to discourage unionization. ${ }^{10}$

4. Alleging unfair labor practices, disputing the choice of bargaining unit, etc. ${ }^{11}$

There are a number of aspects of this process, environment, and context that are relevant to our analysis. First, employers always have the option of voluntarily recognize a union without an NLRB election - which does occur, but much less frequently. In these cases, it is plausible that the union and management are not too far apart on issues such as wages and benefits, seniority pay scales, or grievance procedures. By comparison, in the typical situation - where recognition is achieved through an election - employers are thought to generally oppose organization drives (Kleiner 2001), which is consistent with the notion that both parties perceive to have "something at stake" in the outcome of the election. ${ }^{12}$ Thus

10 For an anecdotal account see Levitt (1993).

11 One example is employers arguing that its employees are not workers but "independent contractors" who are not covered by the provisions of NLRA, see for example, the Dunlop Commission report (1994) and Human Rights Watch (2000).

12 That both union and management expend resources on these campaigns, however, does not constitute proof that both parties care about the outcome of the election, per se. For example, even if a union is expected to receive a clear majority of the vote - so that representation is not the issue - management may attempt to weaken overall support for the union, and union may do just the 
our sample of elections may be biased in favor of finding union effects - at least, compared to voluntary recognition cases, which our data exclude.

Second, combined with a contentious atmosphere, the secret-ballot nature of the vote undoubtedly generates a certain amount of uncertainty in the outcome of the election, particularly when the vote is expected to be close. To appreciate this point, consider a hypothetical situation in which the law states that union certification is to be secured through a public (i.e. "non-secret") petition. If the only requirement were 50 percent or more signatures, the sample of establishments/unions where the unions submitted a petition with 51 percent of the signatures would likely be very different from a (peculiar) group of establishments/unions where the workers submitted signatures that totaled 49 percent. Close winners and losers would be ex ante systematically different, therefore invalidating the regression discontinuity design. Intuitively, there would be significant incentives to obtain the marginal vote in order to exceed the 50 percent threshold; a discontinuity in the density of the share of workers signing the petition would be expected.

It is plausible that in a secret-ballot election that no one knows the exact vote count until all ballots have been submitted, and therefore cannot know for certain whether, for example, the union is one vote shy of a victory. ${ }^{13}$ If true, then it is plausible that the outset of each uncertain election, the ex ante probability density of the vote share can be expected to be continuous. This would imply that the variation in union recognition status that is isolated by the regression-discontinuity design is as good as that from a randomized experiment (see Lee $(2003 a$ ) for a formal proof). We also note that no discontinuous jump up in the distribution of vote shares is apparent in the data, as illustrated in Figure II.

Finally, we note that by focusing on election events within the past two decades, the effects that we estimate are of union impacts in recent years. And there are several reasons to believe that the state of U.S. industrial relations in the last twenty to thirty years has not been favorable for the exercise of union bargaining power. For example, it is widely believed that an important element of a union's power to achieve improvements in wages and working conditions is the threat of a costly strike. But in recent decades, there has been an increased threat and use of striker replacement workers (LeRoy 1995a, Olson 1998). Union leaders believe that President Reagan's large scale replacement of striking PATCO air traffic controllers had a "chilling effect" on the trade unions in the private sector: the industrial relations climate changed so that

opposite.

13 We analyze elections in which there are 20 or more votes cast in the election. 
employers were much less fearful of employing striker replacements (Donohue 1990).

Some researchers have also argued that there has been an intensification of managerial opposition to unionization (Bronfenbrenner 1994, Dickens \& Leonard 1985, Kleiner 2001, LeRoy 1995b), with the increased incidence of unfair labor practices (LaLonde \& Meltzer 1991, Weiler 1983) and use of management consultants to thwart organizing drives and rid employers of existing unions (Lawler 1990, Lawler 1984). Others have argued that other recent developments in the labor market - innovation in labor-saving technologies, and increased openness to international trade - have contributed to union decline (Farber 2001, Katz \& Autor 1999, Acemoglu, Aghion \& Violante 2001).

Given this environment, it is no surprise that survey data suggest that there has been a reduction in the "demand" for unionism, in large part, due to the perception that unions are no longer able to provide a significant value to the worker. Farber (1989), for example, reports a substantial decline between 1977 and 1984 in the fraction of non-union workers that believe that unions improve wages and working conditions. The perception of union weakness is also evident in polling data from Gallup, which indicates that the fraction of people believing that "big labor" is the "biggest threat" to the future of the country fell from 22 percent in 1981 to 9 percent in 1999. ${ }^{14}$

\section{Conceptual Framework and Identification Strategy}

This section describes 1) the different possible notions of the "impact of unionization", and 2) our empirical strategies for identifying two of these notions.

\subsection{What does the "Impact of Unionization" mean?}

"Impact of unionization" is an ambiguous expression, as it could refer to any one of many distinct possible causal effects. The most natural interpretation is the difference between what an employer does in the presence of a union and what the employer would have done in the absence of a union. An ambiguity arises, however, because unions can economically impact employers, even when they appear to be "absent". For example, suppose a union successfully organizes a workplace and bargains with the employer, but both management and the union fail to sign a first contract agreement in the year that follows the election. A

\footnotetext{
14 "Between 1936 and 1965, the period of union-density growth and stabilization, the percentage of the public who approved of labor unions fluctuated between $61 \%$ and $75 \%$. After 1965, with the decline in union density, the percentage approving of labor unions ranged between 55\% and 66\%." The percentage of respondents listing "big labor" as the "biggest threat to the country in the future" fell from $22 \%$ to $9 \%$ between 1981 and 1985. See Cornfield (1999).
} 
union contract may not be in effect, but it is clear that the union may nevertheless affect the employer during that first year. Indeed, even if a contract is never reached, the union's mere presence in the collective bargaining process may pressure the employer to concede on wages, for example.

There is a more subtle possibility. Suppose after a contentious organizing campaign, the union loses the representation election. Following this, responding to the workers' desire for unionization and aiming to prevent further organizing attempts, the employer might raise wages. Here, the "threat" causes the employer to alter its behavior, even though the union - after the election - is even more clearly "absent" than in the previous case.

There are thus multiple interpretations of the notion of the "impact of unionization". In order to differentiate between these different impacts, it is helpful to instead consider more generally the "impact of collective bargaining power" on employers, while recognizing that workers can possess such power either explicitly through a union contract or otherwise implicitly, and whether or not a union is present in collective bargaining negotiations. More specifically, we consider the collective bargaining power of the workers in four different possible states of the world: 1) the union wins the representation election, and thus is authorized as the exclusive representative of the workers in collective bargaining negotiations, 2) the workplace is "non-union" because the union lost the election, 3) it is "non-union" because no election was ever held, and 4) it is "non-union" because the law prohibits unions and collective bargaining activity.

Figure I graphically represents this perspective. It shows the possible relationships between the degree of bargaining power of the workers in a workplace and how voters would vote (in terms of the prounion vote share) if a representation election were held - for four different possible states of the world. $B_{0}(V)$ represents the unrealistic (but important benchmark) scenario in which the law prohibits unions and any kind of collective bargaining activity. Naturally, collective bargaining power is at its minimum, and the extent to which voters would support an organizing drive is irrelevant to their bargaining power.

$B_{M}(V)$ represents the relation when the law does allow unions through elections, but an election has not taken place. This line is potentially higher than $B_{0}(V)$ : employees can implicitly "threaten" to hold an election, and therefore can possess an increased bargaining power. It also could be upward sloping with respect to $V$, if the strength of this implicit bargaining power is related to how workers would vote in a representation election. 
$B_{N}(V)$ is the relation - only existing for $V<50$ percent - when an election is held, but the union loses. It is intuitive that this line would be above $B_{M}(V)$ : the implicit bargaining position of workers would rise as soon as the NLRB determines that an election is to be held. The law prohibits employers from altering wages and benefits during the election, but there may be an implicit expectation that wages and benefits will be higher following the election, even if the union loses. That is, there may be an expectation that the employer will raise wages after the election as an effort to placate the workers and avoid another future attempt.

Finally, $B_{U}(V)$ is the relation - only existing for $V>50$ percent - when the union is victorious in a representation election. The potential gap between $B_{U}(50)$ and $B_{N}(50)$ represents the direct benefit of legal recognition (i.e. winning the election) to the workers' collective bargaining power - keeping all other things equal. In addition, it is again plausible that bargaining power would be related to the union vote share, whether or not the union wins the election; this is reflected by the positive slopes of $B_{U}(V)$ and $B_{N}(V)$.

The regression discontinuity design identifies the response of the employer to an increase in bargaining power, $B_{U}(50)-B_{N}(50)$, that directly results from a workplace becoming unionized. In other words, the RD design identifies the consequences of mandating that an employer bargains "in good faith", and respects the other legal protections afforded to the recognized union. For convenience, throughout the paper we refer to this as the "direct impact of unionization", or simply, the "impact of unionization".

There are three other notions of union "impacts" to consider. First, there is an indirect "threat" effect: even if a union is unsuccessful in its organizing drive, the threat of future organizing attempts can raise the implicit bargaining power of the workers by the amount, $B_{N}(V)-B_{M}(V)$. This shift can, in turn, induce an employer to alter wages, employment, and output. Throughout the paper we refer to this as the "indirect impact of unionization", or "threat effects".

Second, there is the response of employers to a law that permits unions to exist and collective bargaining to occur. Due to the threat of holding an election, and possibly gaining union representation, workers possess greater bargaining power in a world that allows union representation elections, compared to a world where unions are prohibited. The effect of the law is to raise bargaining power by $B_{M}(V)-B_{0}(V)$; this can be the case even if no unions actually form. This effect, while an alternative possibility, is not 
particularly policy relevant in the United States. Mainstream policy discussions have not contemplated the complete prohibition of unions and collective bargaining for the past several decades.

Another possible notion of a union "treatment" is the marginal increase in bargaining power that results from an exogenous rise in union activism and support amongst the workers. This rise in bargaining power would be represented in either $B_{N}(V)$ or $B_{U}(V)$, by movements "along the curve". For example, an exogenous increase in activism might raise $V$ from 60 to 90 percent, raising bargaining power from $B_{U}(60)$ to $B_{U}(90)$, and in turn, causing the employer to accordingly alter wages, employment, and output.

The practical shortcoming of this notion is that there is no way to quantify the impact, as there are no obvious units of measurement for "union activism" or "union support". ${ }^{15}$ Furthermore, this notion has limited policy relevance, since union activism is not a direct instrument of government policy. This stands in sharp contrast with the notion of the direct impact of union recognition, in which: 1) the treatment is dichotomous and easily quantifiable and interpretable (a union becomes the exclusive bargaining representative versus not), and 2) the direct impact corresponds to the effect caused by the government's legal mandate for employers to bargain with the union. ${ }^{16}$

We focus on the first two notions of union "treatments", the direct treatment of union recognition, $B_{U}(50)-B_{N}(50)$, and the indirect threat, $B_{N}(V)-B_{M}(V)$. Apparent from the figure, this two-step approach allows us to consider one exogenous factor at a time. That is, we consider separately the questions: 1. What is the impact of union recognition keeping all other things - including having held an election equal? and

2. What is the impact of having a representation election keeping all other things - including the workplace ultimately remaining non-union - equal?

We consider $B_{U}(50)-B_{N}(50)$ to be the first-order treatment because if the direct impact of legal recognition is zero, so must be the effect of the threat of recognition. To see this, consider the case of wages, using the same subscript notation as in Figure I. Why would an employer promise $W_{N}$ equal to $W_{U}$ (with both greater than $W_{M}$ ) if there is at least some probability that an employer can successfully resist the

\footnotetext{
15 In particular, with this notion, one could be interested in the decrease in employment due to a marginal increase in bargaining power, $d E / d B$. But there are no natural units for $B$. Using wages to measure $B$ is problematic since it would preclude the ability to assess how collective bargaining impacts wages.

16 There is another possible definition of a union effect, a "contract" effect: for all those unions who successfully organize, the difference in employer outcomes between unions who secure a collective bargaining agreement and those who do not. There are two problems with this notion. First, it is not clear that a recognized union not obtaining a first-contract constitutes the "absence" of a union; the legal mandate that an employer must bargain in good faith is immediate after the election, and does not "expire" (unless there is a subsequent decertification). Second - in contrast to the direct impact we examine - the dichotomous status of contract/no-contract does not correspond to any existing government policy or mandate; no law compels either of the parties to sign an agreement.
} 
organizing drive and pay the lower $W_{M}$ instead ${ }^{17}$ The converse is not true: $W_{N}=W_{M}<W_{U}$ (no threat effects; positive direct effects) can easily be a profit maximizing solution - even if a marginal increase in $W_{N}$ would reduce the chance of a union victory. ${ }^{18}$

It is important to note that the notion of separately identifiable direct and indirect impacts of unionization is not sensible for cases where the union overwhelmingly supported (e.g. 90 percent support) or rejected (e.g. 10 percent vote share) the union in an election. For example, the notion of a union obtaining 90 percent of the vote in an election but nonetheless failing to gain recognition makes little sense. ${ }^{19}$ The only reasonable counterfactual would be $B_{M}(90)$, representing the bargaining power of the workers at a workplace where there is substantial union support, but an election has not been held. ${ }^{20}$

In principle, the effects due to $B_{U}(90)-B_{M}(90)$ could be much larger than those due to $B_{U}(50)-$ $B_{N}(50)$. This would severely limit the generalizability of the RD estimates if it were the case that the typical union achieved around 90 percent of the vote. That is, if all unions can be expected to receive overwhelming support, then what determines recognition is not whether a union wins an election, but rather whether or not an election is even held in the first place; as a result, the RD estimate - while credible for the direct union impact - would only be relevant to a small subpopulation of all unions.

In practice, however, the opposite is true, as Figure II illustrates. The figure plots the histograms of vote shares (in support of the union) for both of our samples. It shows that the mode of the distributions are less than 50 percent, and that the winning of an election is clearly a binding factor in the typical unionization event. Elections where the union has marginal support are much more common than those where the union overwhelmingly wins the election. ${ }^{21}$ Thus, even if were possible to credibly identify the impact of

17 To see this formally, consider that the employer is maximizing expected profits

$$
\left(1-P\left(W_{N}\right)\right) \pi\left(W_{N}\right)+P\left(W_{N}\right) \pi\left(W_{U}\right)
$$

where $P(\cdot)$ is the probability of a union victory, which is assumed to be a negative function of the employer's offered wage $W_{N}$, and $\pi(\cdot)$ is profits as a function of the wage. As long as $P\left(W_{M}\right)<1, W_{N}=W_{M}$ will strictly dominate $W_{N}=W_{U}$.

18 The first derivative of the expected profit function in the preceding footnote is

$$
\underbrace{\left(1-P\left(W_{N}\right)\right)}_{(+)} \underbrace{\frac{\partial \pi}{\partial W_{N}}}_{(-)}+\underbrace{\frac{\partial P}{\partial W_{N}}}_{(-)} \underbrace{\left(\pi\left(W_{U}\right)-\pi\left(W_{N}\right)\right)}_{(-)}
$$

Thus, even at $W_{N}=W_{M}$, this overall derivative can be negative. Whether or not the objective function is globally convex or concave throughout the interval $\left[W_{M}, W_{U}\right]$, since $W_{M}$ dominates $W_{U}$, this implies that $W_{N}=W_{M}$ yields the optimum even while $W_{U}>W_{M}$.

19 In practice, in several dozen cases, a union fails to be certified, even with more than 50 percent of the vote; presumably this is due to objections filed by the employer regarding the conduct of the election, which leads to a re-running of the election. These cases constitute a negligible fraction of all elections, as discussed below, and demonstrated in Figure I.

20 The other possibility is $B_{0}(90)$, but as mentioned earlier, this counterfactual has not been contemplated in the literature.

21 For example, in our manufacturing sample, there are many more elections in the 45 to 55 percent vote share range than the 85 
$B_{U}(90)-B_{M}(90)$, such an effect would actually be less representative of the broader population than the quantity identified by the RD design. The RD design estimates a weighted average treatment effect that places more weight on observations whose vote shares are more likely to be close to the 50 percent threshold (Lee 2003a). ${ }^{22}$

\subsection{Regression-Discontinuity Design}

Our main identification strategy is to exploit an experiment that is embedded in NLRB representation elections via a regression discontinuity design. That is, unionization is a deterministic function of the votes in support of the union, where union status is "switched on" when the vote share crosses the 50 percent threshold. As in other regression-discontinuity designs, we attribute evidence of a discontinuous relation between the vote share and an employer outcome to the causal impact of unionization.

Formally, using the reduced-form dummy endogenous variable framework of (Heckman 1978) we have the system of equations

$$
\begin{aligned}
y & =X \gamma+D \beta+\varepsilon \\
D & =1\left[V>\frac{1}{2}\right] \\
V & =X \delta+u
\end{aligned}
$$

where $y$ is the employer outcome (employment, wages, output), $D$ is the indicator of union recognition status, $V$ is the vote share for the union in the representation election, $X$ contains exogenous variables that determine the vote share and $y$, and $\varepsilon$ and $u$ are corresponding unobservable determinants. $\beta$ is the parameter of interest and corresponds to the impact that arises from the union "treatment" $B_{U}(50)-$ $B_{N}(50) \cdot{ }^{23}$

It is widely understood that OLS, which essentially computes the difference $E[y \mid X=x, D=1]-$ $E[y \mid X=x, D=0]$ will be biased for $\beta$, since generally, $E\left[\varepsilon \mid V>\frac{1}{2}\right]-E\left[\varepsilon \mid V \leq \frac{1}{2}\right] \neq 0$. On the other hand, if we assume 1) there is some ex ante uncertainty in the vote share, and furthermore that 2) the density of $u$ conditional on $X$ and $\varepsilon$ is continuous, then it can be shown that the discontinuity in $E[y \mid V=v]$ at

to 95 range - by a factor of 6 .

22 This assumes that before the election, the vote share has a non-degenerate probability density.

23 For expositional purposes, we consider a constant treatment effects model, but the assumption is not important. This can easily be extended to a heterogeneous treatment effect framework. 
$v=\frac{1}{2}$ identifies the union effect (Lee 2003a). That is,

$$
\lim _{\Delta \rightarrow 0^{+}} E\left[y \mid V=\frac{1}{2}+\Delta\right]-\lim _{\Delta \rightarrow 0^{+}} E\left[y \mid V=\frac{1}{2}-\Delta\right]=\beta
$$

Furthermore, Lee (2003a) shows that under these two mild continuity assumptions, the variation in treatment status has the same statistical properties as a randomized experiment; in particular, the distribution of all elements of $X$ and $\varepsilon$ will be approximately the same between the treated and control groups within a small neighborhood of $V=\frac{1}{2}$. This implies that we can test the internal validity of the regressiondiscontinuity design by assessing whether there are discontinuities in the relation between the vote share and any pre-determined characteristic in $X$. That is, a sharp discontinuity in $E[X \mid V=v]$ at $v=\frac{1}{2}$ would provide evidence against the "randomization" and hence the research design.

In empirically assessing whether there are important discontinuities at the 50 percent threshold, we report our RD results in two ways: 1) graphical plots of $E[y \mid V=v]$ and $E[X \mid V=v]$ by 20 equally-spaced vote share categories ${ }^{24}$, and 2) approximating the functions $E[y \mid V=v]$ and $E[X \mid V=v]$ by fourth order polynomials with an intercept shift at the 50 percent threshold. The first method gives a visual impression of 1) the size of any possible discontinuity relative to the underlying "bumpiness"/curvature in the function and 2) possible approximation errors that could occur from using the polynomial specification. The second method estimates the size of the discontinuity and sampling variability.

Some caution is warranted in making statistical inferences from the polynomial regressions. On the one hand, if the fourth order polynomial functions are "correct", the estimator is efficiently using data that are both close to and far from the discontinuity threshold. On the other hand, if the true functions do not belong to the class of fourth order polynomials, the discontinuity estimates will in general be biased, and may lead to erroneous inferences of statistical significance. As shown below, based on our graphical analysis, we determined that the fourth-order polynomial was the most parsimonious specification that would not grossly misrepresent the shape implied by the underlying data; to show this, we super-impose the predicted values from the polynomial on top of the 20 vote share category means. For completeness, we also report results for lower order polynomials.

2420 vote share bins were chosen because it was the largest number of bins that would accommodate the smallest elections in our sample (20 votes cast). See the Appendix for a detailed explanation of the "integer" problem. 


\subsection{Event-Study Analysis of Threat Effects}

Assessing the impact of increased "threat" of unionization while keeping recognition status constant $B(V)_{N}-B(V)_{M}$ - requires a different identification strategy. We utilize the notion that when an employer faces an NLRB representation election, the risk of unionization presumably rises, particularly in the short run. As part of an effort to placate workers and prevent future organzing attempts, after a union defeat in an election, the employer might raise wages.

We employ an "event-study" design to estimate the impact of the occurrence of an NLRB election on the employer - for the sample of elections where we know - ex post - that the union loses and thus fails to gain legal recognition. ${ }^{25}$ By focusing only on the cases where the union loses, we isolate the "threat" effect independently of the direct impact.

We use longitudinal data on manufacturing establishments and estimate the specification

$$
w_{i t}=\alpha_{i}+\gamma_{t}+\sum_{k=-6}^{11} D_{i t}^{k} \delta_{k}
$$

where $w_{i t}$ is $\log$ (average wages) for establishment $i$ in time period $t, \alpha_{i}$ is a time-invariant fixed effect, $\gamma_{t}$ is

a year-effect, and $D_{i t}^{k}$ is a dummy variable that takes the value 1 if the election takes place in period $t-k$, and 0 otherwise. ${ }^{26}$ Elections occur every year throughout the period 1984-1999; the specification above essentially "re-normalizes" time for each establishment to be relative to the year of the election, in order to provide a picture of the typical before- and after-election experience of an establishment. Assuming $\delta_{-7}=0, \delta_{k}$ measure the impact of the event of the election on wages both before and after the election. ${ }^{27}$ If one considers it plausible that the election has no impact on wages more than 2 years before the election event, then the coefficients $\delta_{-3}, \delta_{-4}$, etc. should be zero; those coefficients provide a way to test the over-identifying restrictions of the model.

\section{Data Description}

Our analysis combines several different data sets: 1) the universe of NLRB representation elections held between 1984 and 1999,2) the universe of contract expiration notices from the Federal Mediation and

\footnotetext{
25 We are essentially adopting the approach used in Jacobson, LaLonde \& Sullivan (1993).

267 years and earlier are grouped into one category; 11 years and after are grouped together.

27 In practice, we omit the dummy $D_{i t}^{0}$ so the $\delta_{k}$ are all relative to $\delta_{0}$. The reported coefficients can easily be re-normalized so that $\delta_{-7}=0$.
} 
Conciliation Service (FMCS) from 1984-2001, 3) business survivorship, employment, and estimated sales volume from a commercial database (InfoUSA) with information on population of businesses with a telephone number, as of the year 2001, and 4) detailed employment, output, investment, and wage information from the Census Bureau's Longitudinal Research Database (LRD) on manufacturing establishments in the United States from 1974 to 1999.

We merge these databases to produce two main estimation samples. The first links the NLRB, FMCS, and InfoUSA data, which are used to examine the impact of unionization on business survivorship, employment, and sales volume for a broadly representative sample of establishments "at risk" of unionization, across all industries. The second links the NLRB, FCMS, and LRD data, which are used to examine the impacts on employment, output, productivity, investment, and wages for a representative sample of manufacturing establishments "at risk" of unionization. Appendix Tables I and II provide a summary of the data sets and provides sample means from the two main datasets. Deferring the details to the Appendix, we summarize here the most important features of the two datasets used.

\subsection{The NLRB/FMCS/InfoUSA data}

We first obtained electronic records on all representation election cases handled by the NLRB in the years from 1984 to 1999 . These records have information such as the dates of the filing of the petition, the election, and the closing of the case, as well as the eventual vote tallies, as well as other characteristics such as the size of the voting unit, and the primary industry of the establishment in question. Finally, the records contain the establishment name and exact address. ${ }^{28}$

The names and addresses alone were submitted to a commercial marketing database company, InfoUSA, Inc. InfoUSA maintains an annually updated list of all active business establishments (with a telephone listing) in the United States. The basis for their database is the consolidation of virtually all telephone directories in the country. InfoUSA makes a brief call to each establishment at least once a year, to verify their existence, and to update their information on various items such as 1) the total number of employees at the establishment, 2) the estimated sales volume of the establishment, 3) the primary product of the business, and various other characteristics. InfoUSA appended this information to the record for all of the names and addresses that matched to their database (as of May, 2001). InfoUSA was not given any

$\overline{28}$ Names and addresses are not available for data before 1984. 
information beyond the name of the business and the street address.

This merged data was then additionally linked to a database of all contract expiration notices between 1984 and February, 2001 - more than 500,000 case records - obtained from the Federal Mediation and Conciliation Service (FMCS) through a Freedom of Information Act (FOIA) request. According to the

\section{U.S. Code of Federal Regulations (29 CFR 1425.2)}

In order that the Service may provide assistance to the parties, the party initiating negotiations shall file a notice with the FMCS Notice Processing Unit ... at least 30 days prior to the expiration or modification date of an existing agreement, or 30 days prior to the reopener date of an existing agreement...

Thus, parties to collective bargaining agreements are required to file so-called "30-day notices" with the FMCS. Using these data, we added to the NLRB/InfoUSA data information on whether a contract expiration notice was filed from that establishment. This indicator provided our measure of collective bargaining "activity" both before and after the election.

Note that these data do not provide outcome measures for more than one year, and in that sense is not a true panel dataset. We only observe "survival", employment, or sales as of one point in time - in the year 2001. We observe a few "baseline" characteristics from the NLRB election file, but we do not observe employment or sales during the time between the election and the year 2001 since InfoUSA does not retain historical records.

Also note that, since we are measuring employer "survival" as a match (by name and address) in the InfoUSA database, there will undoubtedly be some measurement error. We will inevitably treat some firms as having "died", when instead InfoUSA was simply unable to match them to their database. On the one hand, this means that that estimates of the level of survival rates may be downward biased. On the other hand, the rate of under-matching by InfoUSA is unlikely to be systematically different between close winners and losers, implying that there will not be a difference in match rates between the two groups, except if there is a true impact of union certification on survival probabilities.

Similarly, our measure of collective bargaining "activity" will also be downward biased in levels. For example, we understate the prevalence of collective bargaining agreements to the extent that our matching algorithm fails to locate a true match in the FMCS data, or that noncompliance with the law (regarding notifying the FMCS when a contract expires) is widespread. ${ }^{29}$ Although the levels of this indicator of bar-

29 Some of this downward bias in levels will also be offset by "false positive" matches. 
gaining "activity" may be biased, it is plausible to assume that these sources of measurement error are not systematically different between close winners and close losers.

\subsection{The NLRB/FMCS/LRD Data}

The second estimation sample is used to investigate the impact of unionization on other variables that are not available in the InfoUSA database: hours worked, investment, and wages. After combining the NLRB and FMCS databases as described above, the resulting database is linked to the U.S. Census Bureau's Longitudinal Research Database (LRD). The LRD is a combination of two different data collection efforts:

1. Census of Manufactures (CM), which is a census of all manufacturing establishments in the U.S., collected every five years (years ending with "2" and "7")

2. Annual Survey of Manufactures (ASM), a set of five year panels, in which large firms are surveyed with certainty, and smaller establishments are drawn from the CM, with new samples being generated every 5 years.

The unit of analysis is a "manufacturing establishment" which is generally defined as a single physical location engaged in one of the categories of industrial activity in SIC Division D, Manufacturing. LRD information is confidential and access is limited although available to qualified researchers. ${ }^{30}$ The survey design is somewhat complicated, but in essence the panel data can be thought of as containing complete annual time-series of information on large manufacturing establishments (greater than 250 employers) and a shorter annual series for a sample of smaller establishments.

\section{Results}

This section reports 1) RD estimates of the impact on recognition status and collective bargaining activity in the short- and long-run, 2) RD estimates for business survival, employment, and output from the NLRB/InfoUSA data, 3) results for survival, employment, output, productivity, investment, and wages from the NLRB/LRD data, 4) estimates for different time horizons and sub-populations and variable definitions, and 5) event-study estimates of "union threat" effects on wages, and effects of "de-unionization" from an analysis of de-certification elections.

\section{$5.1 \quad$ Impact on Collective Bargaining}

We first report evidence that barely winning an election has a lasting impact on legal recognition of the

30 For more detail on the data, see McGuckin \& Pascoe, Jr. (1988). 
union, and has a measurable impact on the collective bargaining process. If winning a close election had little lasting impact on legal recognition status, there would be no need to assess whether there are any discontinuities in economic outcomes, for there would effectively be no "treatment". For example, it is possible that unions who barely win are certain to face a de-certification attempt by the employer; or, it is possible that unions who barely lose an initial election are certain to be victorious in a future election. If either of these possibilities are important in practice, there would be little variation in "treatment" among close elections, making it virtually impossible to assess the impact of legal recognition on employer outcomes.

Figure IIIa provides evidence on the immediate and lasting impact of winning an initial representation election. The solid squares plot the fraction of elections that result in certification of the union, by the union vote share, in 5 percent vote share groups. There are several dozen cases where a union is not certified even after obtaining more than half the votes, or where a union is certified even without obtaining a majority of the vote; these cases are presumably due to NLRB rulings that require a re-run of the election. These cases comprise a negligible fraction of all elections. The fraction immediately recognized is essentially zero below the 50 percent threshold, and essentially 100 percent above the threshold.

Figure IIIa also assesses the hypothesis that unions who barely lose an initial election will inevitably gain recognition in the future. The solid circles represent the probability that a union will eventually gain legal recognition via an election, subsequent to an initial election. Specifically, we focus on elections that take place between 1984 and 1995 and determine whether a union wins in a subsequent election at those employers, using data from 1984 to $1999 .{ }^{31}$ The probability rises with the initial election's vote share, and then drops sharply at the 50 percent threshold, presumably because those who are initially successful do not need to hold another election. Note that some part of the level of the "(2nd) Recognition Later" line is due to a different union gaining recognition at the same employer, as apparent from the right side of the graph. Overall, close losers do seem more likely to eventually gain recognition than unions who lose by a large margin. But close losers of initial elections ultimately have a small chance of eventually being recognized, compared to close winners of initial elections.

Representing the probability that a union will later be de-certified at the employer, the solid triangles in Figure IIIa show that while some fraction of unions who barely win an initial election do become de-

31 So for the 1995 elections, we are allowing 3 years for the union to make another attempt and succeed. 
certified. It is, however, a relatively rare occurrence. The graph implies that about 90 percent of the close winners maintain their union recognition after three years. ${ }^{32}$

There is another scenario that would obviate examining employer outcomes at the 50 percent threshold: if employers were just as likely to engage in collective bargaining with both losers and winners of close elections - despite the difference in legal recognition status. That is, the employer may take 49 percent union support to be a signal that it must inevitably negotiate with the union, and hence choose to voluntarily recognize the union and begin collective bargaining negotiations. If this were true, there would be no discontinuous relation between the union vote share and the probability that a collective bargaining agreement is reached subsequent to the election, for example. It would indicate that the legal mandate that obligates employers to bargain with the union is ineffective.

Figure IIIb rejects this hypothesis. The solid squares plot the probability that an FMCS contract expiration notice is filed at the employer, subsequent to the election. ${ }^{33}$ This dependent variable can be thought of as a proxy for "collective bargaining activity" or a proxy for "bargaining power" $B$, described in Section 3. The proportion sharply jumps from about 15 to 35 percent at the 50 percent union vote share threshold. Some of the 15 percent threshold will be due to "false positive" matches, as well as the presence of a different union at the employer. This is evident from the open squares, which represents the probability that a contract is observed before the election. ${ }^{34}$ Consistent with the hypothesis that the close winners and losers are otherwise similar, this line shows no visible discontinuity in the proportion at the 50 percent threshold. Representing the effective change in collective bargaining activity, the difference in the two lines is very small leading up to the 50 percent vote share cutoff, jumps sharply, and actually declines in the range of 80 to 100 percent. This indicates that there is a greater change in NLRA-induced collective bargaining "activity" for close winners than for unions with overwhelming support.

Figure IIIb also illustrates the value in graphing the entire function $E[y \mid V=v]$, and the danger in relying too heavily on a particular functional form. For the open squares, the jump between the 45-50 and 50-55 vote share categories is not unusual given the jumps between adjacent bins elsewhere in the graph. A

\footnotetext{
32 Again, we use data from the 1984-1995 period for the initial election, and examine whether a successful de-certification attempt occurs thereafter in the 1984-1999 period.

33 Again, elections from the 1984-1995 period were used, and the dependent variable is whether a contract expiration notice was observed subsequent to the election within the 1984-2001 period.

34 Election data from 1987-1999 are used and it is determined whether a contract expiration notice was filed at the establishment prior to the election using the data from 1984-1999.
} 
fourth-order polynomial fit of the function, however, leads to a statistically significant jump of 0.042 with a standard error 0.01. This is an unbiased estimate - if the fourth order polynomial is the "correct" functional form - but will be biased if the fourth order specification is "incorrect." For example, a 7th-order polynomial specification gives a statistically insignificant estimate of 0.026 with a standard error of 0.014 . Given that

- as in all regression discontinuity designs - "statistically significant" results can be sensitive to the choice of functional form, rather than focus singularly on t-statistics, we report point estimates and standard errors from several specifications, and also present the underlying means to provide a visual impression of the expected "bumpiness" one might expect in the function, even in the absence of any true discontinuity.

It should be noted that the observation of a contract expiration notice is not equivalent to whether a union contract is present at the business establishment. In particular, many unions and employers may not comply with the law that requires notifying the FMCS of an impending contract expiration. Evidence on non-compliance or other sources of "under-counting" is provided by an examination of de-certification elections - whereby the employer petitions for an election to determine if a pre-existing union should lose its recognition status. In Figure IIIb, the open and solid circles present analogous lines for whether a contract expiration notice is observed before and after the de-certification election. As expected, the shape of the two lines mirror that of the certification election, with the probability of observing a contract after the election sharply rising at the 50 percent threshold. The probability of observing a contract before the election ranges from 0.40 to 0.50 (the open circles), but should be 1 - if the contract expiration notice variable were a perfect measure of the presence of a union contract. This is thus consistent with undercounting of contracts by about a factor of 2 .

It is also important to note that - even apart from the under-counting issue - our contract expiration notice variable also does not perfectly measure the degree of "bargaining power" of the workers. Just as workers who lose an election can potentially have implicit bargaining power due to the "threat" of unionization, a legally recognized union could pressure an employer to raise wages, even without securing an actual collective bargaining agreement.

\subsection{Analysis of NLRB/InfoUSA: Impact on Survival, Employment, Output}

Derived from the NLRB/InfoUSA data, Figures IV and V present our RD estimates of the impact of unionization on survival, employment, sales, and sales per worker. In Figure IVa, the solid squares plot the 
probability that a business establishment is still in existence as of May, 2001. As mentioned earlier, the employers under consideration are those that held elections between 1984 and 1999. As a result, the business survival effects are averaged over time periods ranging from 2- to 17-year horizons, with more weight given to the longer time-period, since there were more NLRB elections in the mid- to late-1980s.

The solid squares show no visible discontinuity in the survival rates at the 50 percent threshold. Correspondingly, the fourth-order polynomial estimate of the gap yields an effect of -0.012 in probability with a standard error of 0.014 . The mean survival rate is about 0.40 . The precision of the RD estimates are on the same order of magnitude as the theoretical maximum, since a randomized experiment with a 27560 observations would yield a standard error of the difference of about 0.0041 .

The small and potentially null effect on survival is important because it suggests that sample selection bias in an analysis that conditions on survival may be a second order issue. In particular, if the sampling process follows the familiar form of incidental censoring as in:

$$
\begin{aligned}
y^{*} & =X \gamma+D \beta+\varepsilon \\
y & =y^{*} \cdot 1[X \delta+D \phi+v \geq 0]
\end{aligned}
$$

where the outcome $y^{*}$ is only observed if the employer remains in business. If $(\varepsilon, v, X)$ is independent of $D$ - as in a randomized experiment - and if there is no impact of unionization on survival $(\phi=0)$ then there will be no sample selection bias. ${ }^{35}$ As argued above, unionization could be thought of as being randomly assigned (among close elections), and Figure IVa is consistent with a zero impact on survival. In order to evaluate the plausibility of a zero impact - compared to, for a example, a - 0.04 effect that cannot be ruled out due to sampling error - below, we present results on survivorship from a different dataset, as well as explore intensive margin effects.

Figure $\mathrm{IVb}$ presents the $\mathrm{RD}$ estimate for $\ln ($ Employment) for the firms that survive as of the year 2001. Again, no visible discontinuity, and the corresponding point estimate is a statistically insignificant positive effect of 0.029 in logs. Given the standard errors, negative impacts of -0.11 can be ruled out at conventional levels of significance. With these data, then, we cannot rule out a meaningful negative impact on employment. On the other hand, the impact is small compared to the standard deviation in $\ln$ (Employment) of about 1.64 in logs (see Appendix Table II).

$35 \quad$ See Lee $(2003 b)$, for example. 
A similar conclusion is reached from Figure Va, which presents the result for $\ln$ (Total Sales Volume). Again, the jump from the 45-50 to 50-55 percent vote category is not unusually large. The point estimate is not trivial, but it is statistically insignificant -.072. Here, moderately large scale effects cannot be ruled out given the sampling variability of the estimate. The estimates are somewhat more precise when sales is normalized by the size of the employer, as in Figure $\mathrm{Vb}$. The estimated impact on log(Sales/Worker) is -0.053 with a standard error of 0.049 .

A useful feature of our research design is that it generates a number of testable predictions regarding the similarity of employers on either side of the 50 percent union vote threshold. In particular, if in a nearby neighborhood of 50 percent, winning the election is randomly assigned, then any pre-determined characteristic should have the same distribution on either side of the cutoff. The NLRB election contain information on industry as well as the number of votes cast, a proxy of the size of the employer at the time of the election. Figure VIa illustrates that these variables are correlated with the vote share, so that employers where unions win are systematically different from those where the union loses. Where the union wins, the employers are less likely to be manufacturing, and more likely to be service sector establishments. Places where the union either wins or loses by a large margin tend to be smaller. But these systematic differences go away as one examines closer and closer elections. Figure VIa illustrates that there are no striking discontinuities at the 50 percent threshold.

Figure VIb is the analogous graph for the sample of surviving establishments as of the year 2001. Another implication of the near randomized variation and sample selection structure assumed above is that if there is no impact of the treatment on sample selection, the distribution of the pre-determined characteristics should be identical - even conditional on survival. Discontinuity gaps at the 50 percent threshold are not apparent in Figure VIb.

\subsection{Analysis of NLRB/LRD: Impact on Survival, Employment, Output, Capital, and Wages}

The LRD data produces results similar to that yielded by the InfoUSA data: insignificant impacts of unionization on survival rates, as Figure VIIa illustrates. It plots the probability that a manufacturing plant is operating in $1997 .{ }^{36}$ The point estimate is a statistically insignificant -0.026 in probability, compared to a

\footnotetext{
36 In our analysis of the LRD data, we consider a plant to have "survived" by 1997 if it has a valid, non-zero value for total employment, number of production workers, number of production hours, total payroll, and payroll for production workers in the
} 
mean survival rate of about 0.70 . As with the InfoUSA data, the effect is small, and the jump at the 50 percent threshold is actually smaller than most differences from adjacent vote share categories away from 50 percent.

Table I quantifies these results, showing the results from a number of specifications. The mean difference in survival rates between employers where unions won or lost is about 0.07 to 0.08 in probability, and is statistically significant, as shown in Columns (1) - (4). The importance of functional form is demonstrated in Columns (5) - (8), as the difference disappears as polynomial terms in the vote share are added. The estimate in Column (8) corresponds to the fitted regression line in Figure VIIa. As should be the case if unionization is as good as randomly assigned, the estimate does not change significantly as more baseline covariates are added in Columns (9) - (11).

As in the InfoUSA analysis, survival rates are averaged over a range of time horizons, with the elections taking place within the time period 1984-1996. ${ }^{37}$ The solid circles in Figure VIIb represent the average number of years that we observe a plant in operation following the election. Again, no apparent discontinuity at the 50 percent threshold, with a point estimate of less than 20 days. The figure shows that we observe, in the LRD data, a plant in operation for about 5 years, on average, after the NLRB election.

Of course, the open circles are means of censored survival times, since the most recent LRD data for this study is 1999 . To provide an estimate of the plant's survival time following the election, we estimate an interval regression (Tobit) - for each vote share category, and also with the 4th-order polynomial regression specification. ${ }^{38}$ The results are presented as the solid triangles in Figure VIIb. There is little evidence of a distinctive change in survival times between the 45-50 and 50-55 vote share categories, and the point estimate of the gap is a statistically insignificant 0.38 (in years). Given that we find results qualitatively similar to our results from the InfoUSA data, there is empirical justification for now exploring intensive margin impacts - analyzing the sample conditional on survival.

$\mathrm{RD}$ analysis of the LRD data also yields results on bargaining activity, employment, output, and

1997 Census of Manufactures. A Census year must be used because failure to appear in the 1999 ASM, for example, does not necessarily imply a business failure; the plant may not have been chosen for the ASM sample.

37 Since the dependent variable is survival by 1997, the graph does not use elections that take place in 1997 or later.

38 Because the LRD is a combination of a survey and a "census" we can not always identify the precise date that the establishment died, although we can generally pin it down to lying between two different dates where these two dates can be viewed as censoring points. For example, If an establishment is last observed in 1986, then we know it "died" between 1986 and 1987. On the other hand, if last year of the establishment is observed is 1987, then we know it dies between 1987 and 1992; if it is last observed is 1988, then we know it "died" between 1988 and 1992, etc. The dependent variable is then the last year the observation was observed and use the information on the next Census year. For 1998 and 1999, it is only right-censored. Our estimation method is the standard extension to the Tobit. 
output/worker that are similar to those found with the InfoUSA data, as shown in Figures VIII and IX. In each panel in each figure, three lines are plotted. The solid circles represent the means of the dependent variable - by union vote share category - for establishment-year observations in the years that follow the election. A discontinuity at 50 percent represents our estimate of the causal impact of unionization. The open circles represent the means for observations strictly before the year of the election. For this plot, a significant discontinuity at the 50 percent cutoff would indicate that close winners and losers are systematically different before the election, which would imply a problem with the research design.

Finally, the solid triangles plot averages of the dependent variable after it has been deviated from its pre-election mean. That is, in order to reduce the sampling variability in the discontinuity estimate, each post-election observation is deviated from the overall mean that uses all observations before the election, for each plant. In a randomized experiment, this transformation should not affect the impact estimates, since presumably the pre-election mean is independent of treatment status. Similarly, the RD estimates should not be significantly impacted by this deviated-from-means transformation. But the transformation is likely to alter the shape of the function $E[y \mid V=v]$, so it provides yet another specification that can be used to probe the sensitivity of the estimates to choices of functional form.

Figure VIIIa shows a striking discontinuity in the presence of a contract following the election. ${ }^{39}$ This yields the same result as our analysis in Figure IIIb, and the magnitude of the gap will be attenuated for the same reasons. This provides evidence that gaining legal recognition is meaningful in the sense that it induces employers to bargain with the union. Figures VIIIb, IXa, and IXb shows little evidence of a discontinuity in employment (ln(total production man-hours)), output ( $\ln$ (total value of shipments)), or output/hour (ln(total value of shipments/production man-hours)) at the 50 percent threshold. As expected, the shape of the deviated-from-means plots exhibit comparatively less curvature, and less variability across vote share categories, reflecting a reduction in the variability of the dependent variable.

Figure Xa examines capital assets per worker (log(total assets/production workers)). Again, no visible discontinuity at the 50 percent threshold. On the other hand, the quality of asset data in the LRD is somewhat lower than that for employment and output and highly skewed, which could explain the higher

\footnotetext{
39 Given the longitudinal structure of the data, an indicator of contract presence was attached to each year. Since contract expiration notices will not be filed every year, the dependent variable for the LRD data is whether or not a contract expiration notices was filed in the present year or within the last 3 years. Note also, to keep the estimation sample constant, 0 was assigned to all observations in the LRD before 1984, even though we have no NLRB or LRD data before 1984.
} 
variability in the means by vote share.

By contrast, our estimates for wages (log(production payroll/production man-hours)) appear to be reasonably precise, as shown in Figure $\mathrm{Xb}$. Apparent from the deviated-from-means variable, changes from one vote share category to the next do not exceed 5 percent. Against this background variability, it is difficult to discern any discontinuity at the 50 percent vote share cutoff.

Table II presents point estimates of the discontinuity gaps in Figures VIII-X, as well as the results from various specifications. Column (1) reports the simple difference in means, comparing the 50-55 percent to the 45-50 percent vote share categories. Column (2) only includes an indicator variable for whether the union won the election, and Columns (3) - (6) add linear, quadratic, cubic, and quartic terms in the union vote share variable. In Column (7), the dependent variable is the post-election outcome minus the pre-election mean. Column (8) adds the pre-election mean as a regressor, Column (9) adds year dummies, and Column (10) adds 2-digit industry dummies.

The first row shows that the estimated impact of a union victory on the filing of a contract expiration notice is consistently large and statistically significant across specifications. The simple difference in Column (1) is about 0.22 and is about 0.18 in the full specification in Column (10). By contrast, the second and third rows (production hours, output) reports estimates that are much more sensitive to the choice of functional form. They illustrate the danger in relying on one particular specification, and the benefit from showing a larger number of specifications and reporting graphically the means for each vote share category, as in Figures VIII-X. For example, the coefficient on the union victory in the hours equation is -0.20 and is statistically significant in the quadratic specification. On the other hand, adding a cubic term changes the coefficient to 0.085 with a standard error of 0.08 . That estimates of the discontinuity gap could be so sensitive to functional form may not be surprising, given the significant curvature of the function, as illustrated in Figure VIIIb.

We favor the specifications in Columns (7) - (10) - particularly for the second and third rows because there is much less curvature in the functions for the "de-meaned" variables, as apparent in Figures VIIIb and IXa. The point estimates for production hours range from -0.024 to 0.028 ; the most precise estimate (Column 10) implies that a 8 percent decline in hours can be statistically ruled out. For output, the estimates range from -0.043 to 0.011 with the most precise estimate ruling out a 10 percent negative 
impact.

For output/hour - our measure of "productivity" - the estimates are relatively more stable across specifications, and the estimates in Columns (7) to (10) are also more precise. Point estimates range from a impact of -0.015 to -0.019 with a standard error of 0.035 . The results are somewhat less precise for assets/worker, with estimates ranging from -0.136 to -0.029 , all statistically insignificant.

The last row of Table II shows that the estimated wage effects are small, with relatively small standard errors. In fact, all but one of the estimates are negative. Among Columns (7) to (10) the estimates range from -0.026 to -0.016 . Consistent with the overall picture presented in Figure $\mathrm{Xb}$, the 15 to 20 percent union wage effect that is typically estimated from household survey data is easily statistically rejected in the LRD data. Among these estimates, the largest positive wage effect that is within two standard errors of the point estimate is about 0.014 .

\subsection{Estimates for Different Time Horizons, Sub-populations, and Outcomes}

Freeman \& Kleiner (1990) note that as far back as Douglas (1930) it has been conjectured that union wage effects were most likely to be found in first contracts than during the "later and more mature years of union development". We explore this in Table III. Using the full specification in Column (10), the table reports the estimates for different time horizons following the election. Columns (1), (2), and (3) only include establishment-year observations that are 0-3 years, 4-7 years, and 8 or more years after the election, respectively. ${ }^{40}$ For the observation of a contract expiration notice, the effect is 0.077 in the $0-3$ year period - which is to be expected since a contract less likely to expire within the first three years following the election. The estimate rises sharply to 0.307 for year 4 to 7 , as shown in Column (2).

The second through fifth rows show results similar to those in Table III, for each time period: small, positive, and statistically insignificant impacts on hours and output, and small, negative, and statistically insignificant impacts on output/hour or assets/worker. The point estimates are relatively stable across different time horizons.

Finally, the wage effects are also relatively stable. 4 to 7 years after the election, the unionization impact is estimated to be -0.025 with a standard error of 0.021 . After 8 years, the estimated impact is -0.005 with a standard error of 0.028. Again, effects of 15-20 percent can be rejected, and the largest positive wage

40 Pre-election observations are kept for constructing the "pre-election mean". 
effects that are within two standard errors of the point estimates are 0.017 in years 0 to $3,0.017$ in years $4-7$ and 0.051 in year 8 or later.

Table IV reports an analysis of the impacts by different sub-populations. We do this to investigate whether or not our results in the aggregate are masking important effects that vary by important observable dimensions. For reference, Column (1) repeats the estimates from Column (10) in Table II. In Columns (2) and (3) we split the sample by the number of votes cast. The effects for plants with greater than 75 voters are more positive - for all outcomes except assets/worker - but they are not statistically different from those for the smaller plants.

As noted in Appendix Table I, the LRD estimation sample is restricted so that the ratio of eligible voters (as measured from the NLRB) to the number of production workers (from the LRD) is greater than 0.5. When the affected bargaining unit is small relative to the number of production workers, it is natural to expect the impact on production hours and wages to be small. Thus, this restriction makes it more likely to detect an effect. Columns (4) and (5) explore this issue further. In Column (4) the ratio is relatively close to one $(\mid \ln ($ ratio $) \mid<.285)$, and in Column (5) the ratio is farther away from one $(\mid \ln ($ ratio $) \mid \geq 0.285)$. If a large absolute ratio is due to pure mis-matching of the observations across datasets, one would expect the effects to be closer to zero in Column (5). To the contrary, the point estimates for employment and output are more positive in Column (5), although not statistically significant.

In Columns (6) and (7) the sample is stratified by whether the NLRB and LRD street address strings exactly matched. To the extent that our matching algorithm - which attempts to match names and addresses even when the strings from the databases are not exactly the same - generates false positive matches, true negative impacts on hours and output, or true positive impacts on wages, could be attenuated towards zero. To the contrary, however, estimates are more positive for hours and output, and more negative for wages in Column (6), compared to Column (7). More direct evidence on the quality of the match between the NLRB and LRD is provided in Appendix Table III. Regressions of $\ln$ (production workers) from the LRD on ln(eligible voters) from the NLRB yield slope coefficients of about 0.95 to 0.98 with standard errors of about 0.017 , with no important difference between the plants that did or did not exactly match to an NLRB record on the basis of the street address.

Finally, in Columns (8) and (9) the plants are divided into "high-wage" and "low-wage" indus- 
tries. $^{41}$ There is a large difference in estimates for assets/worker, but it is not statistically different from zero at conventional levels, given the sampling variability. There do not appear to be important differences for the other outcomes.

As a final robustness check, we estimated effects for different measures of labor "inputs" (total employment, non-production employment), “outputs" (accounting for changes in inventories), "productivity" (different ratios of outputs to inputs), "capital/labor" (different employment measures as denominator), and "wages" (annual earnings for all workers, non-production workers, including supplementary labor costs). Using the specification in Column (10) from Table II, these estimates are reported in Appendix Table IV. The table shows that for each broad category, the estimates are stable across different definitions of the outcome.

\subsection{Threat Effects and De-Unionization Effects}

Figure XIa reports estimates of the effect on wages due to a "threat effect" - denoted by $B_{N}(V)-B_{M}(V)$ in Section 3. It plots the estimated coefficients $\delta_{k}$ from Equation 3, which represents the effect of an election taking place at an establishment on wages, while keeping the non-union status constant. That is, Figure XIa uses only establishments where the union ultimately lost the certification election, and plots the level of wages in years preceding and following the election - including plant fixed effects, and calendar year effects. Each "year-relative-to-election" coefficient is reported relative to year 0, the year of the election, and the upper and lower 95\% confidence bounds are plotted as well.

The figure shows that wages are relatively stable in the 7 years leading up to the election. They fall by less than 3 percent in that 7 -year pre-election period. The relative stability of the wages before the election provide support for this "event-study" design. Wages are also relatively stable for up to 11 years after the election, with point estimates of wage growth in the post-election period ranging from 0 to 2 percent over the entire period. A 3 percent wage increase by year 3 can be statistically rejected.

For completeness, we include Figure XIb, the analogous picture that restricts the sample to those plants where the union lost with a vote share between 30 and 50 percent. The point estimates - tending

\footnotetext{
41 More specifically, every establishment was assigned the mean $\ln$ (production wage, 2000 dollars) of its industry. Then the industries were categorized into "high" or "low" groups based on whether the mean ln(wage) was greater or less than the median "assigned" wage in the sample.
} 
to center around zero throughout the post-election period - indicate that wages do not rise significantly following an election. Due to the smaller sample size, the confidence intervals are slightly wider, although it is still true that a 3.5 percent wage increase after 3 years can be ruled out at conventional levels of significance. Note, finally, that there is some evidence of a decline in wages prior to the election, suggesting that this particular "before-after" design may be less appropriate for the sub-sample of close elections, compared to the overall sample of union losses, as in Figure XIa.

The analysis thus far has primarily focused on certification elections - the most common case in which a workplace changes its union status. The other possibility is when a union loses in a de-certification election. There are important differences in the interpretation of the effects from each of these distinct events. Union victories in certification elections clearly represent "new" unionization, while union defeats in de-certification elections represent the elimination of unionization that could have occurred many years ago. Also, because de-certifications are less common, the estimates from these cases will necessarily be

less precise. Nevertheless, for completeness, we report the de-certification RD estimates in Figures IV and $\mathrm{V}$ (represented by the solid circles) for the InfoUSA data and Appendix Tables V, VI, and VII for the LRD data. Overall, they show similar results for employment, capital/worker, and wages with point estimates being less than 7 percent in absolute value. The main difference is that for the LRD data, the point estimates are much larger in magnitude for output, and consequently output/hour: they range from negative 15 to 25 percent. The standard errors for all of these estimated effects are substantially larger, and thus both large and small impacts cannot be statistically rejected for many of the outcomes.

\section{Interpretation and Relation to Previous Literature}

In this section, we discuss the interpretation of our five principal findings. First, we conclude from Figures IIIa and IIIb, that the impact of winning a "close" election on union recognition is immediate and lasting, and that unionization causes an employer to respond in at least one way - by raising the probability of reaching a collective bargaining agreement with the union. That the treatment of unionization is lasting, even at the 50 percent vote share threshold is perhaps not surprising. After all, by law, if a union loses a representation election, an "election bar" prohibits an election for at least a year under NLRB rules if the union loses. During this intermediate period, the workers do not enjoy the rights provided by the NLRA to 
unionized workers; the employer has considerable leeway to recruit workers who can be expected to have less sympathy with the unionization attempt.

Second, two independent data sets (InfoUSA and LRD) suggest that the impact of unionization on employer survival - the "extensive margin" of employment - is small. Point estimates are close to zero and statistically insignificant. It is possible that the effects are, for example, negative 0.04 on a mean survival rate of 0.40 , but that we are unable to statistically detect such a magnitude. This interpretation would be particularly plausible if we found substantial union effects on the "intensive margin" of employment. Indeed, it would be somewhat puzzling to find large impacts on employment with no impacts on employer survival. Our most precise estimates (from the LRD data), however, can rule out negative employment effects of 8 percent or larger.

Third, the two data sets yield small point estimates of the impacts on employment (workers or hours), output, and measures of productivity. From the InfoUSA data, estimates of the impact on employment, output, and output/worker range from positive 3 percent to negative 8 percent. For the LRD data, point estimates range from positive 3 percent to negative 2 percent. There are two plausible interpretations of these results. On the one hand, unionization may induce a moderate employment effect, but sampling variability in the estimates prevents us from detecting such magnitudes. For example - even if our point estimate for the effect on hours is positive 0.028 - we could not statistically reject a 6 percent negative response to unionization. This is easily consistent with a $15-20$ percent union wage effect and a 0.33 to 0.4 labor demand elasticity. ${ }^{42}$ On the other hand, the impact on employment may actually be somewhat smaller than 6 percent, potentially because unionization may not lead to a 15-20 percent wage increase in the first place. For example, a 5 percent wage increase, with a 0.33 to 0.4 labor demand elasticity would lead to a reduction in employment of about 2 percent, which is also consistent with the point estimates for employment.

We favor the latter interpretation in light of our fourth, and potentially most important, finding: very small wage effects, with estimates precise enough to statistically rule out both 2 percent wage effects for up to 7 years following the election, as well as 6 percent wage effects thereafter. Even if one ignores the possibility that workers could gain bargaining power through union recognition even without a contract, and inflates the estimates by $1 / 0.55-0.55$ being an estimate of the fraction of the NLRB certifications that

42 This would be assuming that the only impact of unionization on employment occurs through raising the wage. 
result in an initial contract ${ }^{43}$ - it is still true that a 4 percent wage effect can be statistically ruled out within 7 years after the election. ${ }^{44}$

Finally, we find little evidence that workers benefit from increased wages when an employer faces an increased risk of unionization. Focusing on cases where we know ex post that the union loses the election, after accounting for permanent heterogeneity in wages across employers, and year effects, there appears to be little change in wages in the years leading up to and following a certification election. While we deem these "threat effect" estimates to be less reliable than our estimates of the direct impact of unionization, the "event-study" specification does pass the specification test of finding no impact of the election on wages that are determined several years prior to the election event.

Although our results may seem surprising in light of the large empirical and theoretical literature on union "effects", there are a number of simple reasons for the differences. One reason for the discrepancy is that the data we examine are for employers that switched from non-union to union status during the 19841999 period. By contrast, estimates of union wage premium typically utilize data on the current "stock" of union and non-union employers. Even if the union wage premium were zero for recently unionized firms, it may be averaged with union wage premiums for older, more-established employers that were organized many decades ago. Another reason for the difference is that we examine establishment-level data, while most union wage studies examine individual worker-level data. Thus, some part of the observed crosssectional wage gap in household survey data may be attributable to plant-level heterogeneity in the level of wages. Indeed, using establishment-level data, Freeman \& Kleiner (1990) and Lalonde et al. (1996) either find wage effects much smaller than the typical 15-20 percent premiums found in individual-level data, or no effect at all.

A final, related possibility is that the existing literature that is based on household survey data may be identifying a conceptually distinct union "treatment effect". As Heckman (1990), Freeman \& Kleiner (1990) and others have observed, the empirical literature on union wage effects has not always been clear on precisely what effect is being estimated. Studies using household-level data would seem to be addressing

\footnotetext{
43 According to Federal Mediation and Conciliation Service (2003), anywhere between 54.8 and 58.3 percent of NLRB certifications result in an agreement being reached in a given fiscal year. This roughly agrees with the 55 percent figure in the Dunlop Commission report (1994).

44 Note that, for this inflated estimate to represent the effect for this particular sub-population of unions, it is necessary to assume that the mandate that requires employers to bargain with the union has no impact on wages for those unions who do eventually do not secure a contract. To the extent that this is not true, the blow-up factor of $1 / 0.55$ is too large.
} 
the question How much would a randomly-chosen individual gain is moved from the non-union sector to the union sector? Implicit in this question is the presumption that the "randomly-chosen" individual is moved from a "randomly-chosen" non-union employer to a "randomly-chosen" union employer. In the present analysis, we are striving to answer, instead, How much more does an employer have to pay its workers when it becomes unionized? To the extent that unions could form at high-wage employers, it is quite possible to estimate a large union/non-union wage gap at the level of the individual without estimating a large causal impact of unionization on wages at the level of the employer.

As far as theoretical models of the impact of unions are concerned, there is a long history upon which to draw. The mere existence of a "union wage premium" was the subject of considerable debate until the 1960s. Writing in 1950, Milton Friedman argued that "Unions ... have not had an extremely important effect, to date, on the structure of wage rates" arguing inter alia that in a competitive economy, the labor demand elasticity facing labor unions would vitiate any attempt on their part to raise wages.

\section{Conclusion}

As emphasized above, collective bargaining power is not only a function of the rights afforded to unionized workers under the NLRA. It is also a function of the amount of union activism, support, and solidarity amongst its members. Thus our results do not necessarily imply that unions have no potential to substantially raise wages for its members. Instead, our analysis suggests that in they simply have been less than successful in doing so in recent years. We have suggested one reason for this - that unions may be somewhat constrained the competitive pressures that their employer faces in the larger labor market. In the future, the balance of these various factors may change: existing labor laws may either be modified or enforced to a greater degree in favor of unions, or worker attitudes towards unions may shift to encourage activism and solidarity. The advantage of the research design employed here is that since it is a byproduct of the way in which unions are formed in the United States, as long as that system remains, there will always be a way to provide an up-to-date quasi-experimental assessment of the impacts of unions on employers.

At a minimum, by carefully considering the concept of a "causal effect" of unionization, this paper suggests that inferring such effects from worker-level datasets without firm-level information can be problematic. This is because the unionization that can affect employees and employers, occurs at the establish- 
ment level. Indeed, the employer-level analysis on wages presented here yields estimates that substantially depart from those obtained from typical individual-level data.

In light of this, there are several potential directions for future research. First, since the wage data were only available in the LRD, our estimates of the wage impacts apply only to the manufacturing sector. As employer-level datasets are becoming increasingly available to researchers, it will be possible to examine union wage impacts in the service sector. Second, our analysis focuses on average wages, but unions may have a minimal impact on average wages, while substantially affecting the distribution of wages. The impact of unionization on the internal wage structure within the establishment can also be studied. Finally, there are a number of non-wage aspects of jobs that can be affected by the pressures of collective bargaining, including the adoption of particular labor-saving production technologies, the rate of employment turnover, and safety in the workplace. The research design employed here should be useful for pursuing these avenues of empirical investigation. 
Abowd, J. M. (1989), 'The effect of wage bargains on the stock market value of the firm', American Economic Review 79(4).

Acemoglu, D., Aghion, P. \& Violante, G. L. (2001), 'Deunionization, technical change, and inequality', Carnegie-Rochester Conference Series on Public Policy 55, 229-264.

Blanchflower, D. G. \& Bryson, A. (2003), What effect do unions have on wages now and would 'what do unions do' be surprised?, Working Paper 9973, National Bureau of Economic Research, Cambridge, MA.

Bronars, S. G. \& Deere, D. R. (1993), 'Union organizing activity, firm growth, and the business cycle', American Economic Review 83, 203-220.

Bronfenbrenner, K. (1994), Employer behavior in certification elections and first contracts: Implications for labor law reform, in S. Friedman, R. Hurd, R. Oswald \& R. Seeber, eds, 'Restoring the Promise of American Labor Law', ILR Press, Ithaca, New York, pp. 75-89.

Campbell, D. T. (1969), 'Reforms as experiments', American Psychologist 24(4), 409-429.

Commission for Labor Cooperation (1997), 'Plant closings and labor rights: A report to the council of ministers on the effects of sudden plant closings on freedom of association and the right to organize in canada, mexico, and the united states'.

Commission on the Future of Worker-Management Relations (1994), 'Fact finding report', U.S. Department of Labor, U.S. Department of Commerce, Washington D.C.

Cornfield, D. B. (1999), 'Shifts in public approval of labor unions in the united states, 1936-1999', Guest Scholar Poll Review. www.gallup.com/poll/guest_scholar/gs 990902 .asp.

Dickens, W. T. \& Leonard, J. S. (1985), 'Accounting for the decline in union membership, 1950-1980', Industrial and Labor Relations Review 38(3), 323-334.

Donohue, T. (1990), Testimony of Thomas Donohue, Secretary Treasurer of the AFL-CIO, in 'Preventing Replacement of Economic Strikers 1990: Hearing on Senate 112 Before the Subcommittee on Labor of the Senate Committee on Labor and Human Resources, 101st Congress, Second Session'.

Douglas, P. H. (1930), Real Wages in the United States, 1890-1926, Houghton Mifflin, Cambridge, Mass.

Farber, H. S. (1989), 'Trends in worker demand for union representation', American Economic Review 79(2). Papers and Proceedings of the Hundred and First Annual Meeting of the American Economic Association.

Farber, H. S. (2001), 'Accounting for the decline of unions in the private sector, 1973-1998', Journal of Labor Research 22(3).

Federal Mediation and Conciliation Service (2003), Fifty-sixth annual report, Technical report.

Freeman, R. B. (1985), Why are unions faring poorly in NLRB representation elections?, in T. Kochan, ed., 'Challenges And Choices Facing American Labor', MIT Press, Cambridge.

Freeman, R. B. \& Kleiner, M. (1990), 'The impact of new unionization on wages and working conditions', Journal of Labor Economics 8(1), S8-S25.

Freeman, R. B. \& Kleiner, M. M. (1999), 'Do unions make enterprises insolvent', Industrial and Labor Relations Review 52(4), 510-527.

Freeman, R. B. \& Medoff, J. L. (1984), What Do Unions Do?, Basic Books, New York.

Friedman, M. (1950), Some comments on the significance of labor unions for economic policy, in D. M. Wright, ed., 'The Impact of the Union: Eight Economic Theorists Evaluate the Labor Union Movement', Harcourt, Brace and Company, New York. Institute on the Structure of the Labor Market, American University, Washington D.C.

Hahn, J., van der Klaauw, W. \& Todd, P. (2001), 'Identification and estimation of treatment effects with a regression-discontinuity design', Econometrica 69(1), 201-209.

Heckman, J. (1978), 'Dummy endogenous variables in a simultaneous equation system', Econometrica 
46, 931-960.

Heckman, J. (1990), 'Varieties of selection bias', American Economic Review 80, 313-318.

Hirsch, B. T. (2004), What do unions do for economic performance?, in J. T. Bennett \& B. E. Kaufman, eds, 'What Do Unions Do? The Evidence Twenty Years Later', chapter 6.

Hirsch, B. T. \& Schumacher, E. J. (1998), 'Unions, wages, and skills', Journal of Human Resources 33(1), 201-219.

Human Rights Watch (2000), 'Unfair advantage: The freedom of association in the united states under international human rights standards'.

Jacobson, L., LaLonde, R. \& Sullivan, D. (1993), 'Earnings losses of displaced workers', American Economic Review 83(4), 685-709.

Katz, L. F. \& Autor, D. H. (1999), Changes in the wage structure and earnings inequality, in O. Ashenfelter \& D. Card, eds, 'Handbook of Labor Economics', Vol. 3, North Holland, Amsterdam.

Kleiner, M. (2001), 'Intensity of management resistance: Understanding the decline of unionization in the private sector', Journal of Labor Research 22(3).

Lalonde, R. J., Marschke, G. \& Troske, K. (1996), 'Using longitudinal data on establishments to analyze the effects of union organizing campaigns in the united states', Annales D'Economie et de Statistique 41/42, 155-185.

LaLonde, R. J. \& Meltzer, B. D. (1991), 'Hard times for unions: Another look at the significance of employer illegalities', University of Chicago Law Review 58, 953-1014.

Lawler, J. J. (1984), 'The influence of management consultants on the outcome of union certification elections', Industrial and Labor Relations Review 38(1), 487-501.

Lawler, J. J. (1990), Unionization and Deunionization: Strategy, Tactics, and Outcomes, University of South Carolina Press, Columbia, SC.

Lee, D. S. (2003a), Randomized experiments from non-random selection in u.s. house elections, Unpublished manuscript, University of California, Berkeley.

Lee, D. S. (2003b), Trimming for bounds on treatment effects with missing outcomes, Unpublished manuscript, University of California, Berkeley.

LeRoy, M. H. (1995a), 'The changing character of strikes involving permanent striker replacements, 19351990', Journal of Labor Research 16, 423-437.

LeRoy, M. H. (1995b), 'Regulating employer use of permanent striker replacements: Empirical analysis of NLRA and RLA strikes 1935-1991', Berkeley Journal of Employment and Labor Law 16(1), 169-208.

Levitt, M. J. (1993), Confessions of a Union Buster, Crown, New York, NY. With Terry Conrow.

Lewis, H. G. (1963), Unionism and relative wages in the United States, University of Chicago Press, Chicago.

Lewis, H. G. (1986a), Union relative wage effects, in O. Ashenfelter \& R. Layard, eds, 'Handbook of Labor Economics', Vol. 2, North Holland, Amsterdam, chapter 20, pp. 1139-1182.

Lewis, H. G. (1986b), Unionism relative wage effects: A Survey, University of Chicago Press, Chicago.

Mankiw, G. N. (2004), Principles of Economics, third edn, Thomson Southwestern, Mason, OH. Chapter 26.

McGuckin, R. H. \& Pascoe, Jr., G. A. (1988), The longitudinal research database (lrd): Status and research possibilities, CES Working Paper 88-2, Center for Economic Studies, U.S. Bureau of the Census, Upper Marlboro, MD.

Nickell, S. \& Layard, R. (1999), Labor market institutions and economic performance, in O. Ashenfelter \& D. Card, eds, 'Handbook of Labor Economics', Vol. 3C of Hanbook in Economics, Elsevier Science, New York, chapter 9, pp. 473-521.

Olson, C. A. (1998), The use of strike replacements in labor disputes: Evidence from the 1880s to the 
1980s. Paper presented at the 1999 Winter meetings of the IRRA, New York City.

Ruback, R. \& Zimmerman, M. (1984), 'Unionization and profitability: Evidence from the capital market', Journal of Political Economy 92, 1134-1157.

Thistlethwaite, D. \& Campbell, D. (1960), 'Regression-discontinuity analysis: An alternative to the ex post facto experiment', Journal of Educational Psychology 51, 309-317.

Weiler, P. (1983), 'Promises to keep: Securing workers' rights to self-organization under the NLRA', Harvard Law Review 96, 1769, 1772-1773. 


\section{Appendix A. Data Appendix}

The NLRB to InfoUSA match First, electronic records on all representation election cases handled by the NLRB in the fiscal years 1984 to 1999 were obtained. These records contain information such as the dates of the filing of the petition, the election, and the closing of the case, as well as the eventual vote tallies, as well as other characteristics such as the size of the voting unit, and the primary industry of the establishment in question. Most importantly the file contains information on the name and street address at which the representation election was held.

These 139,881 records were then matched by name and address to a commercial marketing database company called InfoUSA, Inc. Before being sent to InfoUSA, however, the address fields were first "standardized" using a program called "Mailers +4 Postal Automation Software." For example, "1 Broad Street" was changed to "1 BROAD ST". This was done to facilitate matching the NLRB data to the data from InfoUSA.

As discussed in the text, InfoUSA maintains an annually updated list of all business establishments (with a telephone listing) in the United States. The basis for their database is the consolidation of virtually all telephone books in the country. InfoUSA makes a brief call to each establishment at least once a year, to verify their existence, and to update their information on various items such as 1) the total number of employees at the establishment, 2) the estimated sales volume of the establishment, 3) the primary product of the business, and various other characteristics.

We submitted the name and address information from our "address standardized" NLRB data to InfoUSA who matched as many of the submitted records to their current database (as of May, 2001) and then appended their information to the record. Apart from the name and address information, no other information was given to InfoUSA.

Before merging this data to our data from the Federal Mediation and Conciliation Service (described below) the data were cleaned for duplicates. There were three types of duplicates: 1) genuine duplicates - more than one NLRB case with a specific employer, 2) duplicates which where an artifact of the fact that our NLRB data came in two files: one contained data from 1977 to 1991 and the other contained the records for 1984-1999. Most of the duplicate pairs therefore occurred for the years 1984-1991, although there were some duplicate pairs in other years because of the fiscal/calendar year distinction; 3) a 
very small number of duplicates where two records containing exactly the same information.

Matching Algorithm: NLRB to FMCS and NLRB to LRD Matching records between the NLRB and FMCS and between the NLRB and LRD data involved the following procedure. Matching was done on the basis of the company name, street address, city, and state, which are elements in each of the three datasets. First, all datasets were stripped of special characters such as @,\#, \%, \&, *, etc. Then, "common” words were stripped from both the name and address fields. For example, "COMPANY", "CORPORATION", "INC", "CO", "STREET", "AVENUE", etc. What was considered "common" was based on a complete cataloging of all words in the NLRB and FMCS database. The words were ranked by their frequency, and the most frequent ones were considered "common". For each case in the NLRB, the algorithm isolated the subset of records in the FMCS (LRD) that matched exactly on city name and USPS state abbreviation. Within this smaller subset, the NLRB record's name and address were compared to the corresponding entries in the FMCS (LRD). For each comparison, a "spelling distance" (the function SPEDIS in SAS) was created. The spelling distance is a number from 0 to 100 indicating the difference between two strings. 0 means an exact match, and 100 indicates no similarity. An index that combined the name and address spelling distances were constructed, and all comparisons where the index was below a particular threshold was considered a "match".

In particular, the coefficients for the name and address spelling distances, as well as the threshold was determined in the following way. 100 records were chosen randomly from the NLRB database. We conducted a manual search for matches in the FMCS database using regular expression searching ("grep" in Unix). We called the matches that resulted from this non-automated procedure "true" matches. Then a dataset was constructed that attached to each of the randomly chosen 100 records from the NLRB, all the records from the FMCS in the same city. Each observation in this "expanded" dataset, then, is assigned a " 1 " if the pairing is a "true match" (as determined by the manual search), and "0" otherwise. Using this dataset, a probit was run using this indicator variable as the dependent variable and the spelling distances for name and address as the independent variables. The coefficients from this probit (including the constant) are used to construct the index described above; inclusion of the constant in this index implies that 0 is the optimal threshold for deciding what is a match.

Note that in order to make the algorithm invariant to the order in which NLRB records are matched, 
the matching algorithm is done "with replacement". That is, multiple NLRB records could potentially match to the same FMCS (LRD) record.

With the LRD data, each establishment can have multiple names (due to spelling differences, orders of names, and ownership changes), each corresponding to one year within the longitudinal database. ${ }^{45}$ Thus, NLRB records tended to match to several different names, and it was necessary to pick the single "best" match. This was done by first eliminating all names of establishments for years that were equal to or greater than the year of the election. Then, among the remaining matches - which all had indices greater than 0 the highest match index was chosen. The single establishment that had that highest index was assigned to the NLRB record. Again, note that it is possible, given matching "with replacement" that more than one NLRB record can match to the same establishment. Therefore, all standard errors are clustered at the level of the establishment.

Sample Selection and Variable Construction First, in order to minimize measurement error in our survival indicator, we keep only those NLRB records that have a non-missing street address, and those addresses that were successfully standardized using our address standardization software. In addition, we keep all elections in which 20 or more votes were cast. Appendix Table I reports the means and standard deviations of the variables for the entire merged database and the restricted sample used for the estimation. The table shows that the means are reasonably similar between the two samples, except in the variables that reflect the scale of the employer (number of eligible voters, votes cast, employment, sales volume).

Finally, great care was taken to construct the vote share for the union. There is a problem with simply computing the ratio of the number of votes for the union to the total number of votes. This is because there is substantial variability in the number of votes cast, and a union victory is secured by obtaining strictly more than 50 percent of the vote (plus 1 vote). Consider all elections where an even number of votes are cast. Elections with any number of votes cast could result in exactly 50 percent of the vote. However, it is impossible that an election with less than 100 votes cast could have a vote share between 50 and 51 percent of the vote. This mechanically induces a discontinuity in the size distribution at the 50 percent threshold of the vote share, and this is entirely an artifact of the fact that the vote share is not literally continuous, and instead has finite and discrete support, with the support changing with the number of votes cast.

45 More specifically, the LRD itself does not contain names and addresses. It must be merged on from the Standard Statistical Establishment List (SSEL) - via a unique identifier that links the two data sets. 
Thus, we made a minor adjustment to the vote share variable in order eliminate this problem. For every case where there was an even number of votes cast, an amount equal to $0.5 /$ (\# votes cast) was subtracted from the vote share. For example, if 25 out of 50 votes were for the union, the vote share became $0.50-0.01=.49 ; 26$ out of 50 votes meant a vote share of $0.52-.01=0.51$. Cases where an odd number of votes cast were unadjusted. This minor adjustment restores symmetry in the support for vote share, and the new "vote share" variable still possesses the property that strictly more than 0.50 implies a union victory. Finally, the vote share was "binned" so that all vote shares between 0.50 and 0.55 were assigned the vote share of 0.525 , shares between 0.45 and 0.50 were assigned the share of 0.475 , and so forth. In this way, vote shares were standardized to the support for the elections with the smallest number of votes cast (20).

A completely different approach is to abandon the use of the vote share completely, by focusing on the absolute vote count, and comparing elections in which the union either won or lost by literally 1 vote. This eliminates this "integer problem", but at the same time tends to push larger establishments away from the threshold that determines victory (generating a pronounced U-shape in the average size of the establishment, with respect to the absolute vote margin of victory/loss). This was the approach used in DiNardo and Lee [2001]; it should be noted that the results reported there are qualitatively and quantitatively similar to the results in this paper, suggesting that our findings are not sensitive to the method used to address the integer problem. 


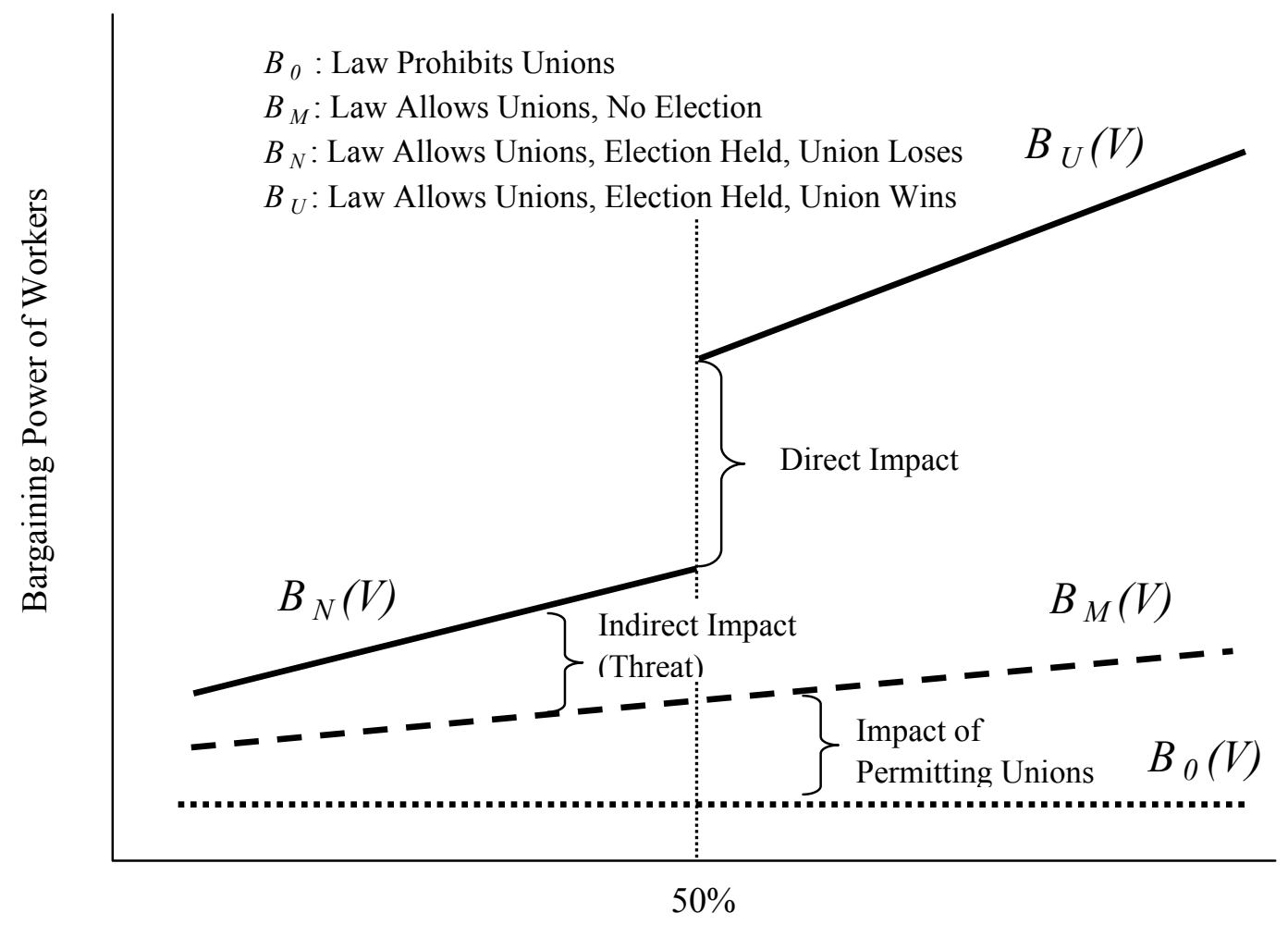

Vote Share (How Workers Would Vote)

Figure I

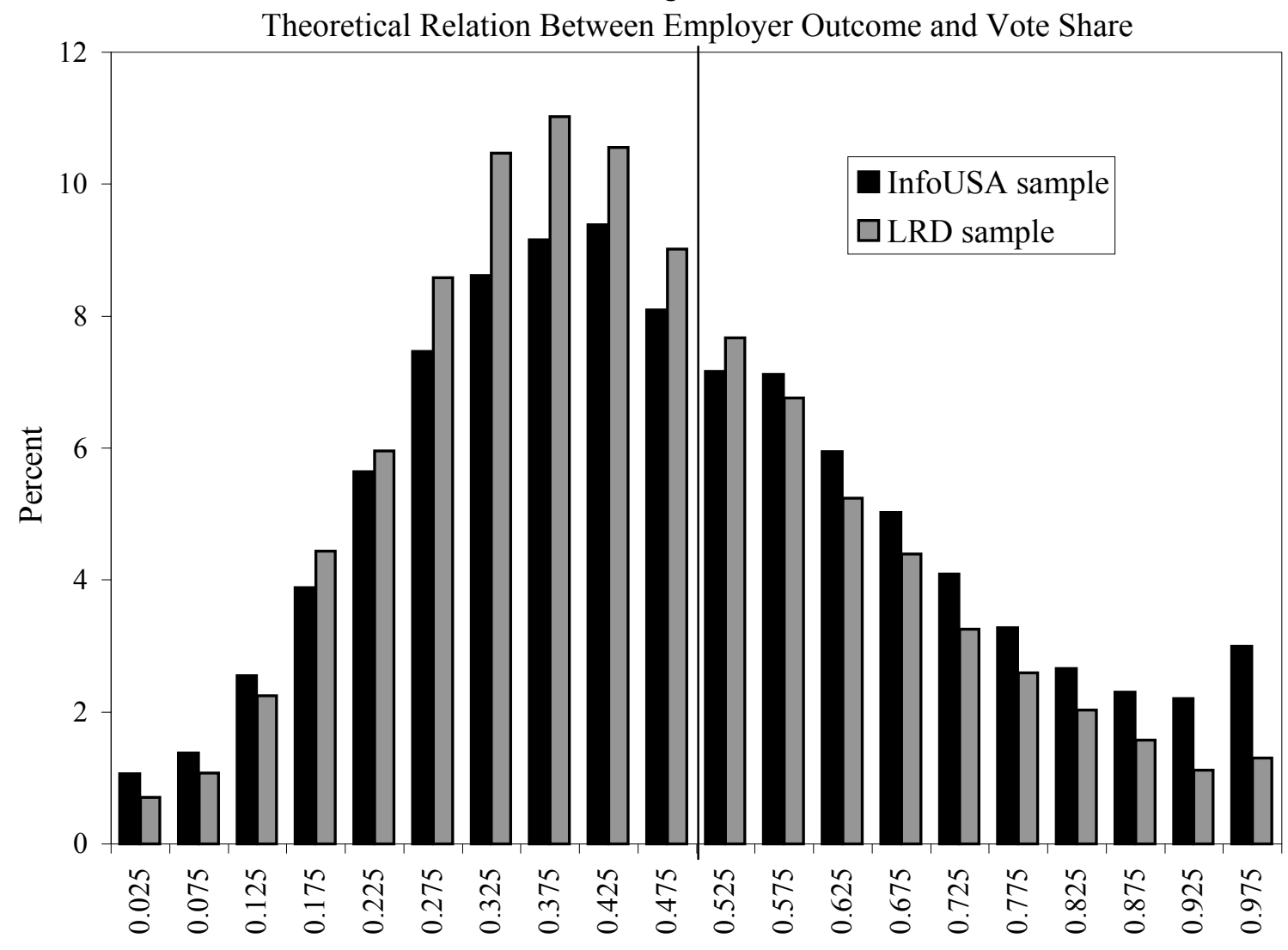

Union Vote Share

Figure II

Distribution of Union Vote Share, All Certification Elections, InfoUSA and LRD sampl 
Figure IIIa: Recognition, Subsequent Certification or Decertification, by Union Vote Share

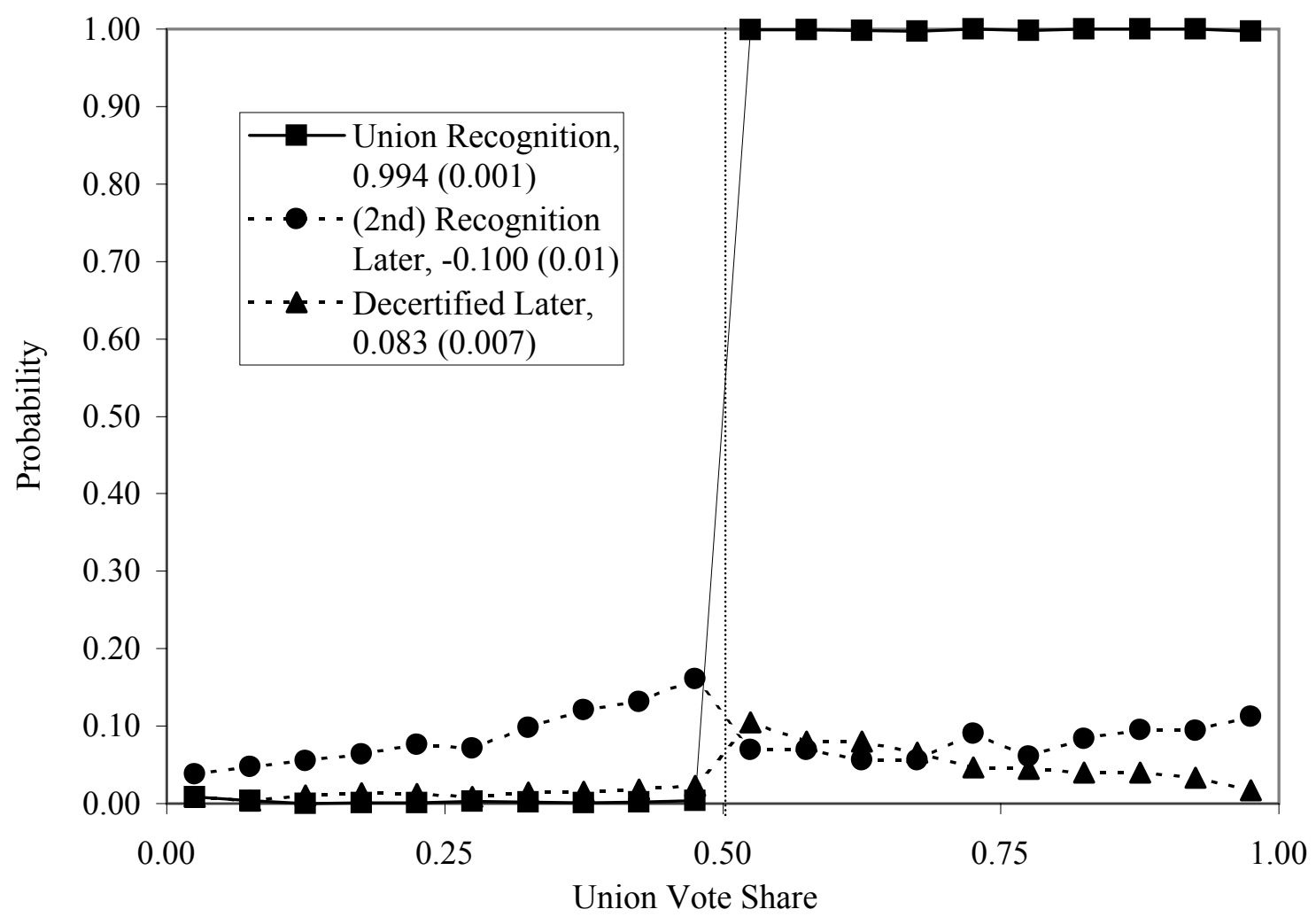

Note: 21405 Observations

Figure IIIb: Contract Expiration Notice Filed, Prior to and Post-Certification or

Decertification Election, by Union Vote Share

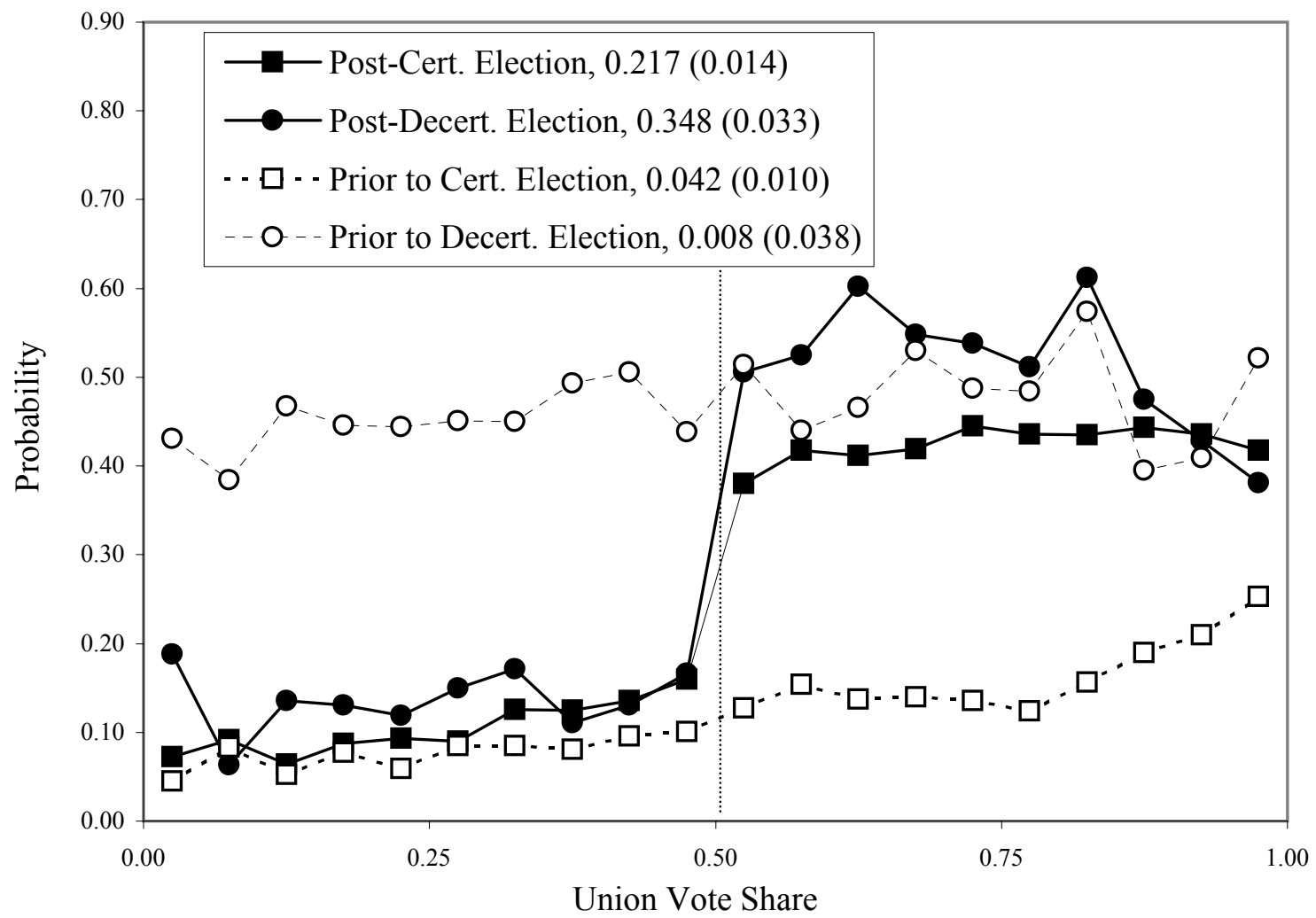

Note: $21405,3785,21457$, and 3445 Observations, respectively. 
Figure IVa: Survival at Year 2001, by Union Vote Share

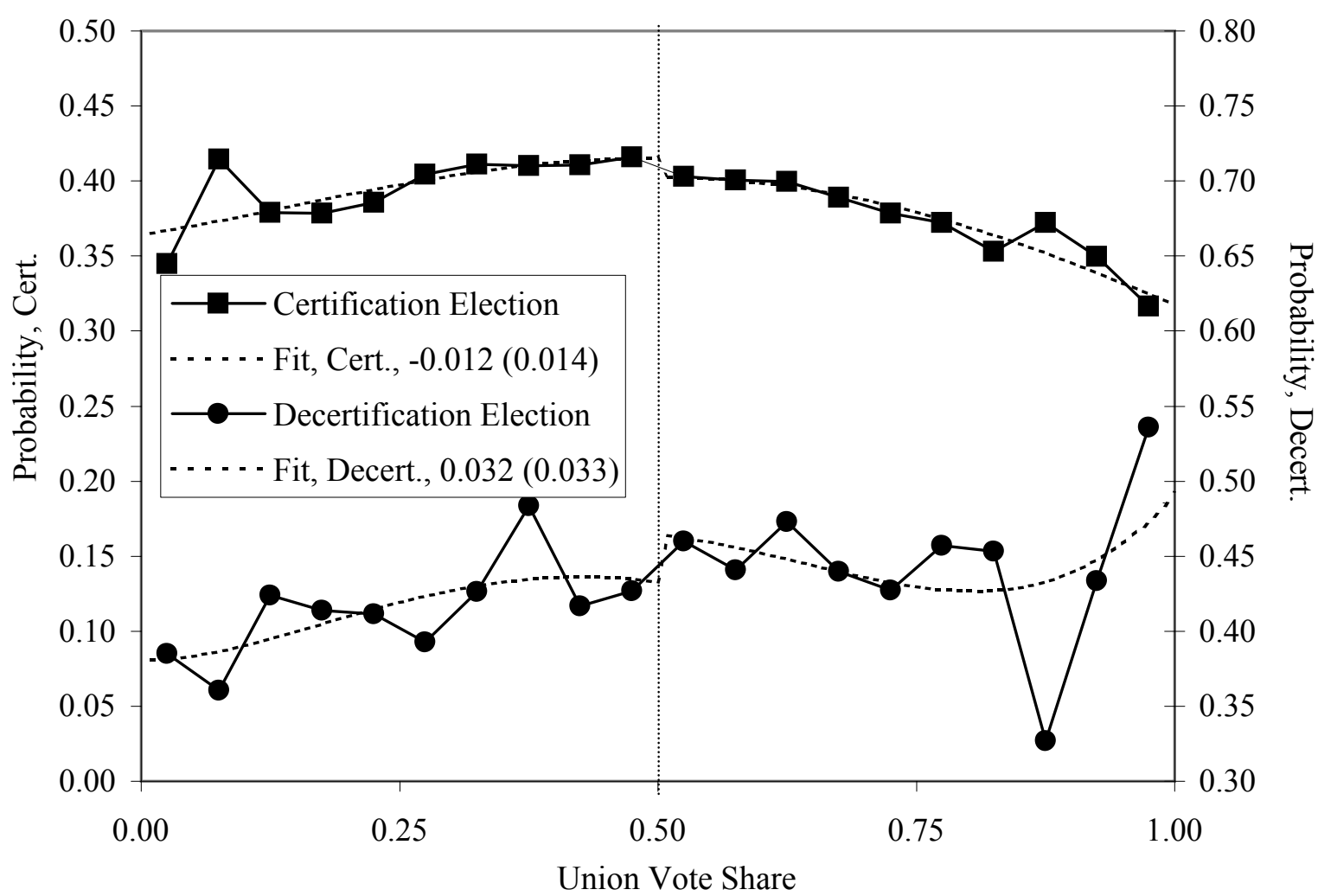

Note: 27560 and 4638 observations, respectively.

Figure IVb: Log(Employment), Year 2001, by Union Vote Share

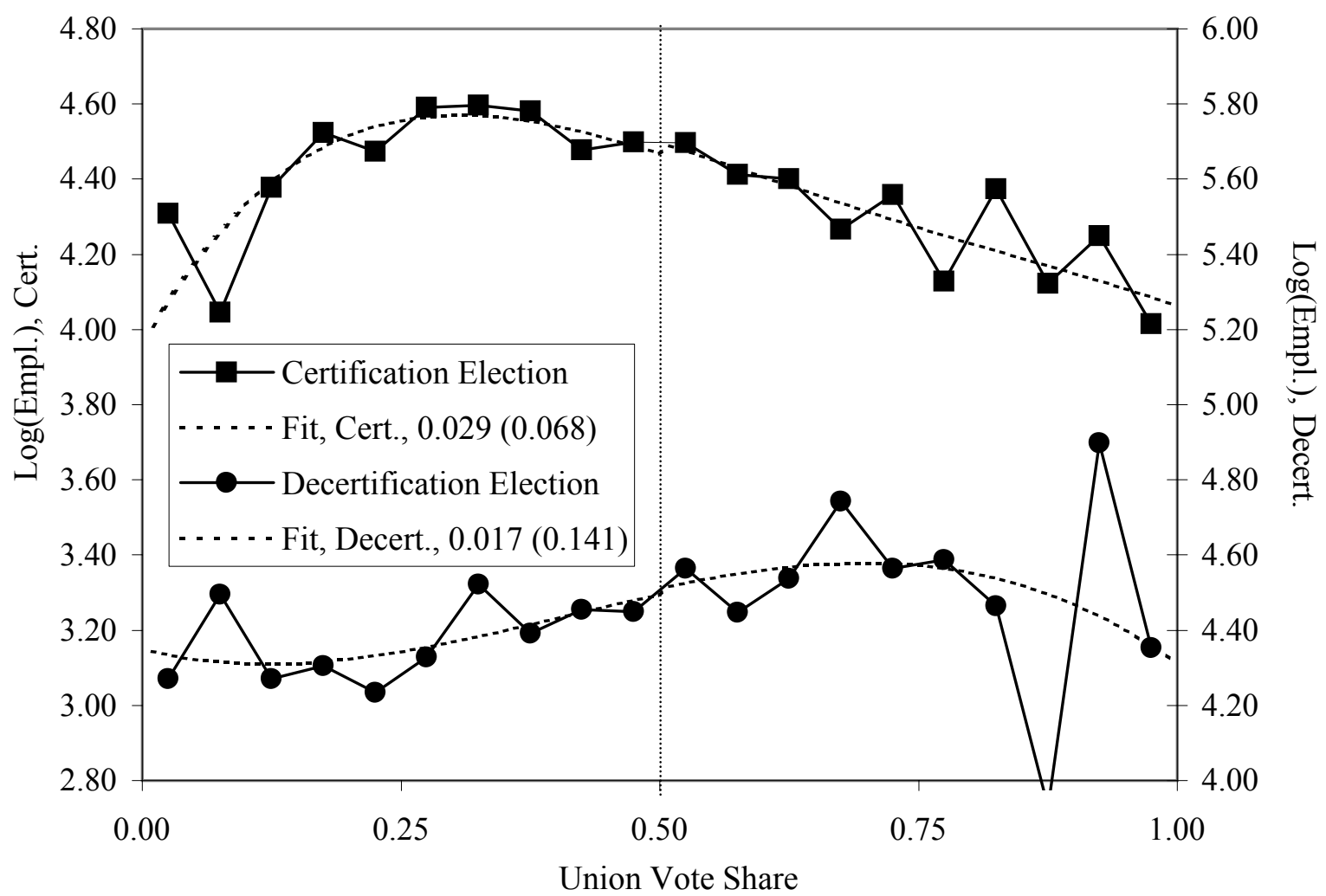

Note: 9792 and 1857 observations, respectively. 
Figure Va: Log(Sales), by Union Vote Share

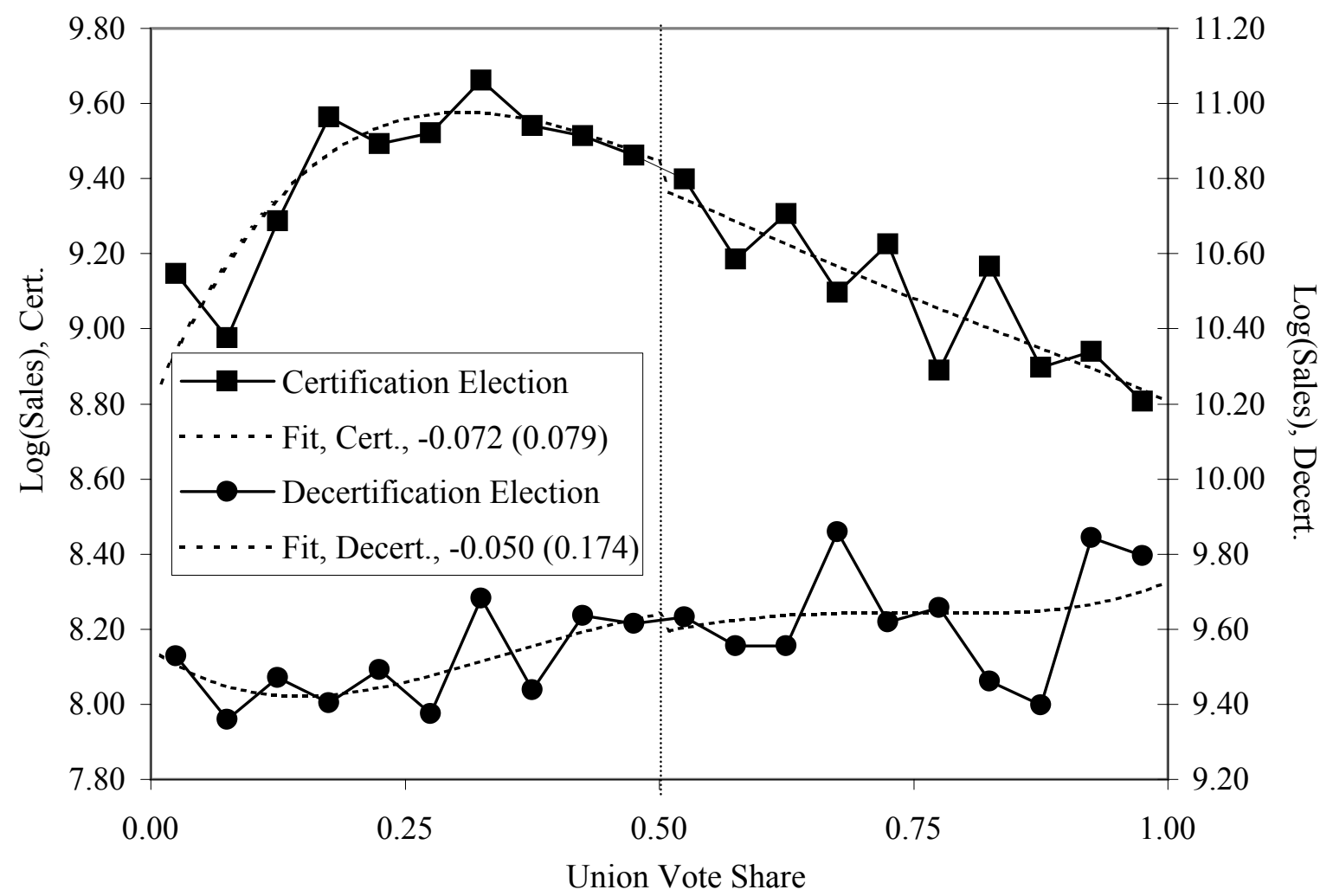

Note: 9125 and 1738 observations, respectively.

Figure Vb: Log(Sales/Worker), by Union Vote Share

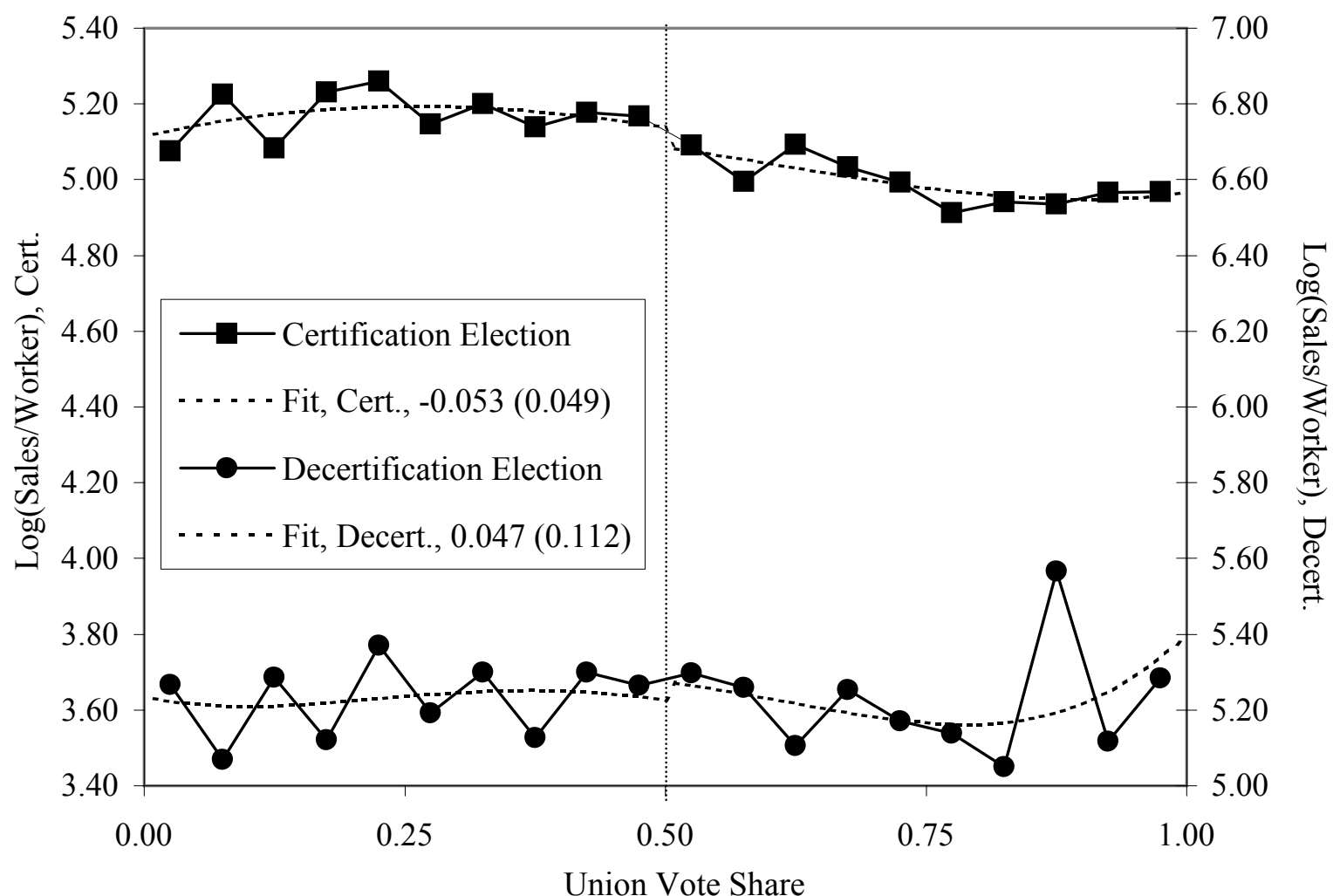

Note: 8634 and 1674 observations, respectively. 
Figure VIa: Baseline Characteristics at Time of Election, by Union Vote Share

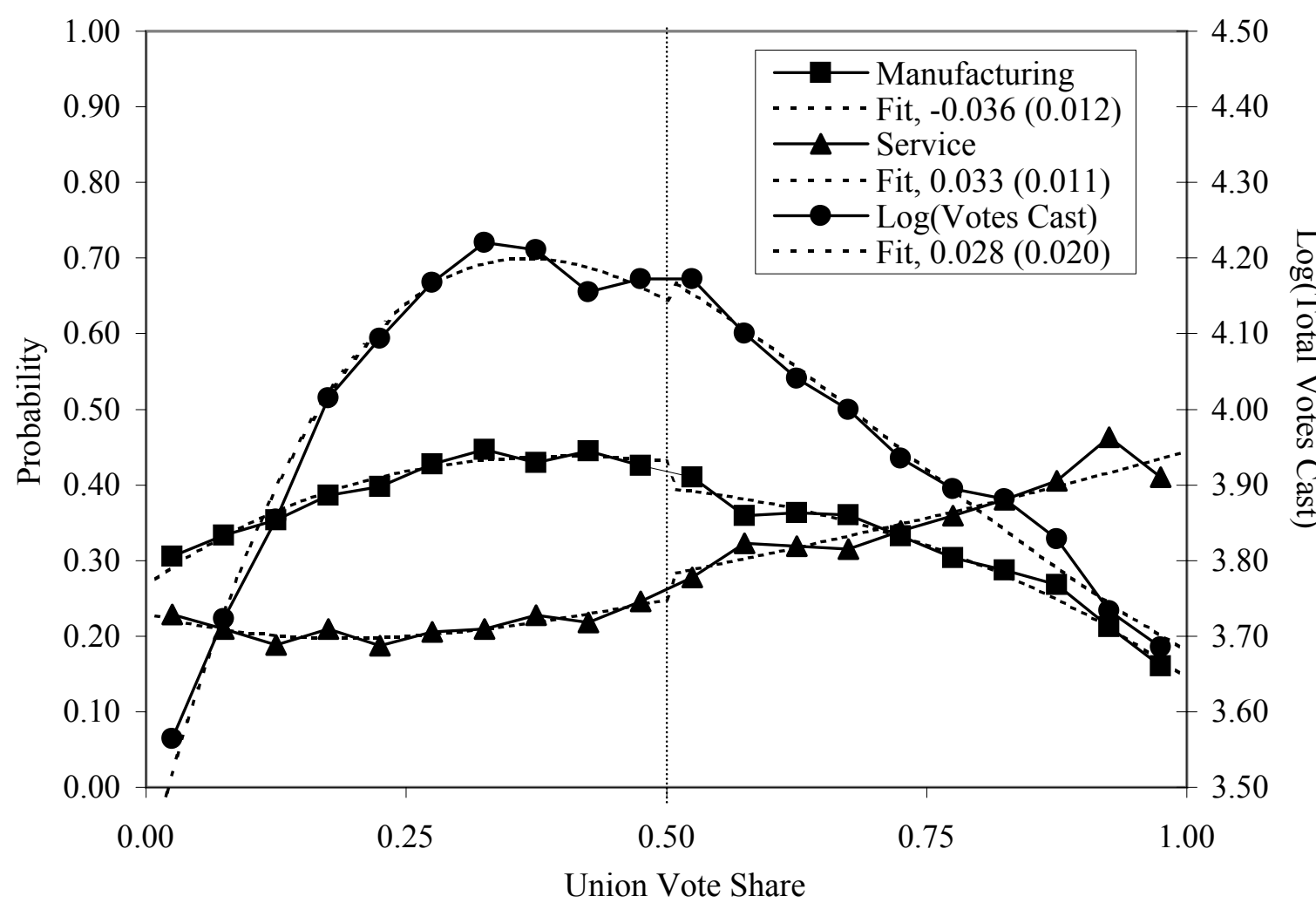

Note: 32198 observations

Figure VIb: Baseline Characteristics at Time of Election, Conditional on

Survival at Year 2001, by Union Vote Share

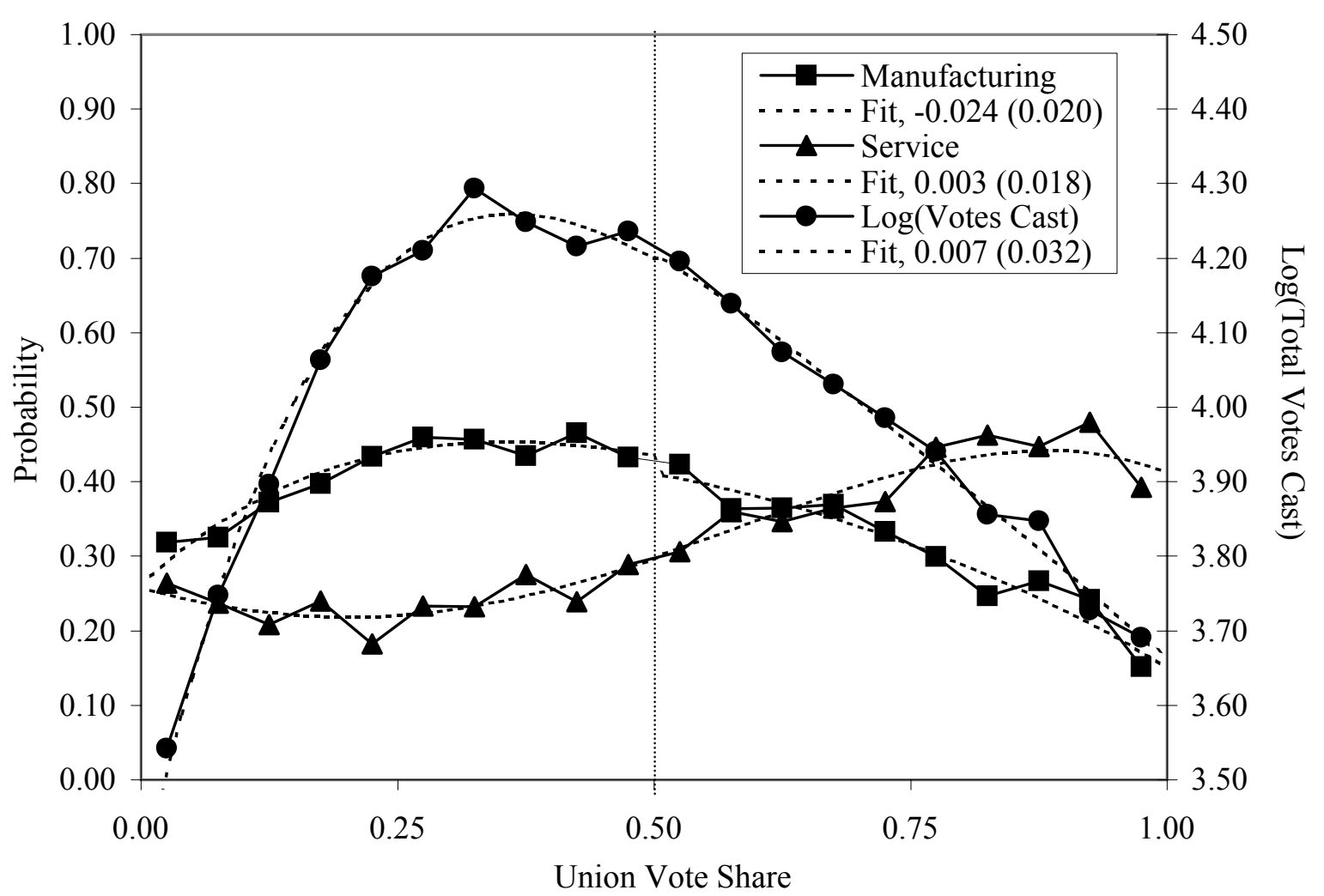

Note: 13062 observations 
Figure VIIa: Survival at Year 1997, by Union Vote Share, LRD

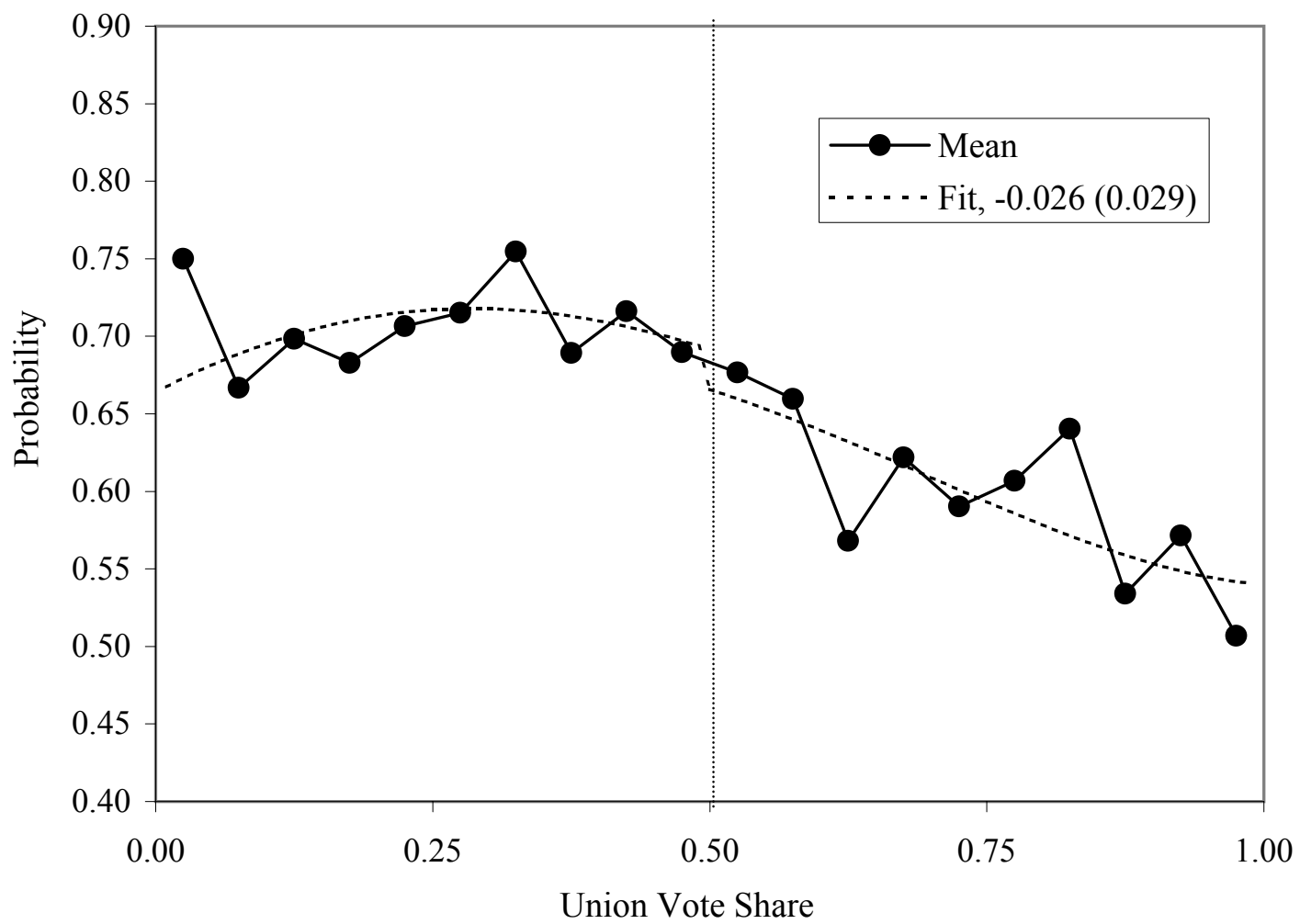

Figure VIIb: Last Year Observed and Years in Business Since Election, by Union Vote Share, LRD

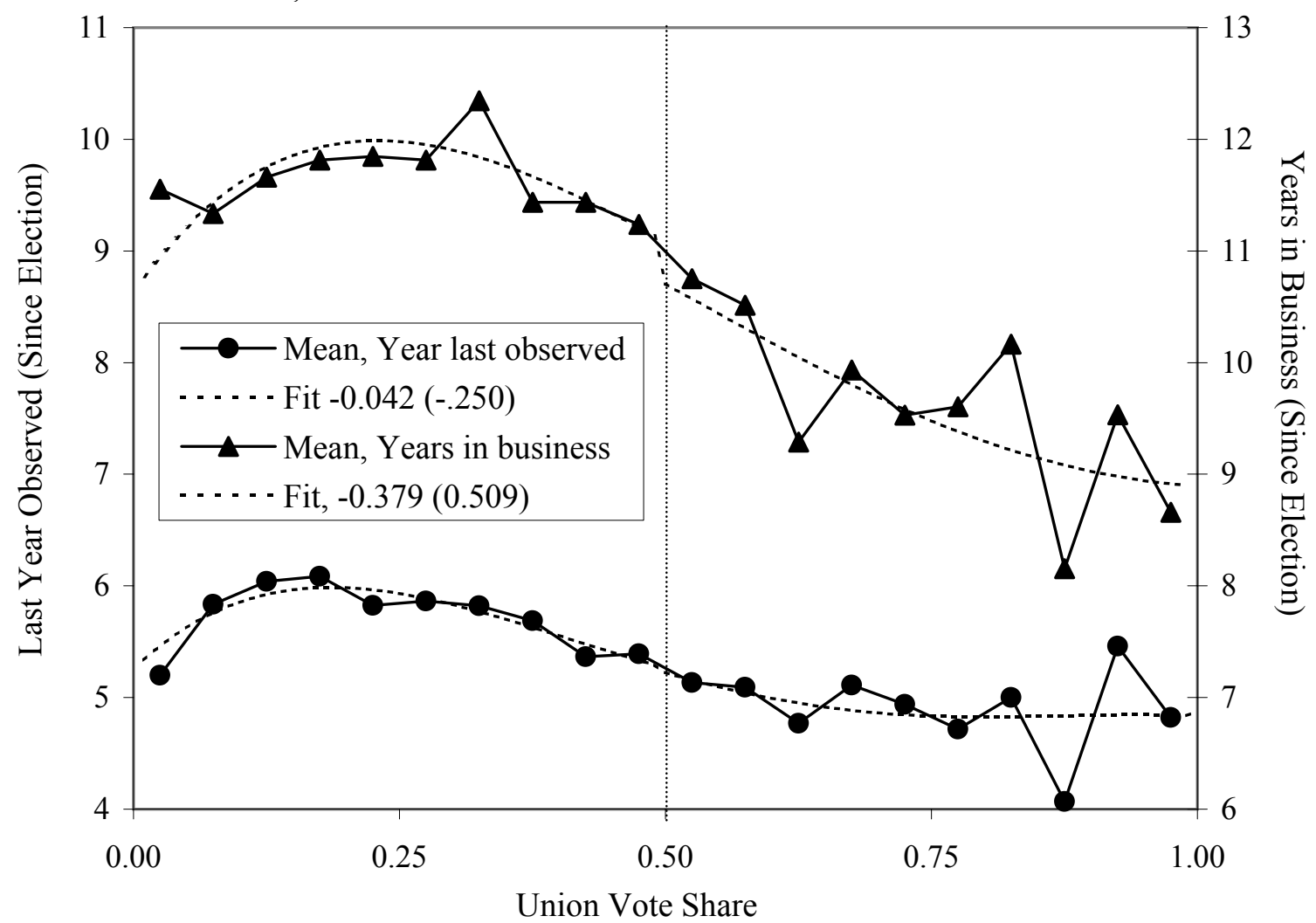

Note: 5608 Observations, 4816 Establishments 
Figure VIIIa: Observation of a Contract Expiration Notice, Pre- and

Post-Election, by Union Vote Share, LRD

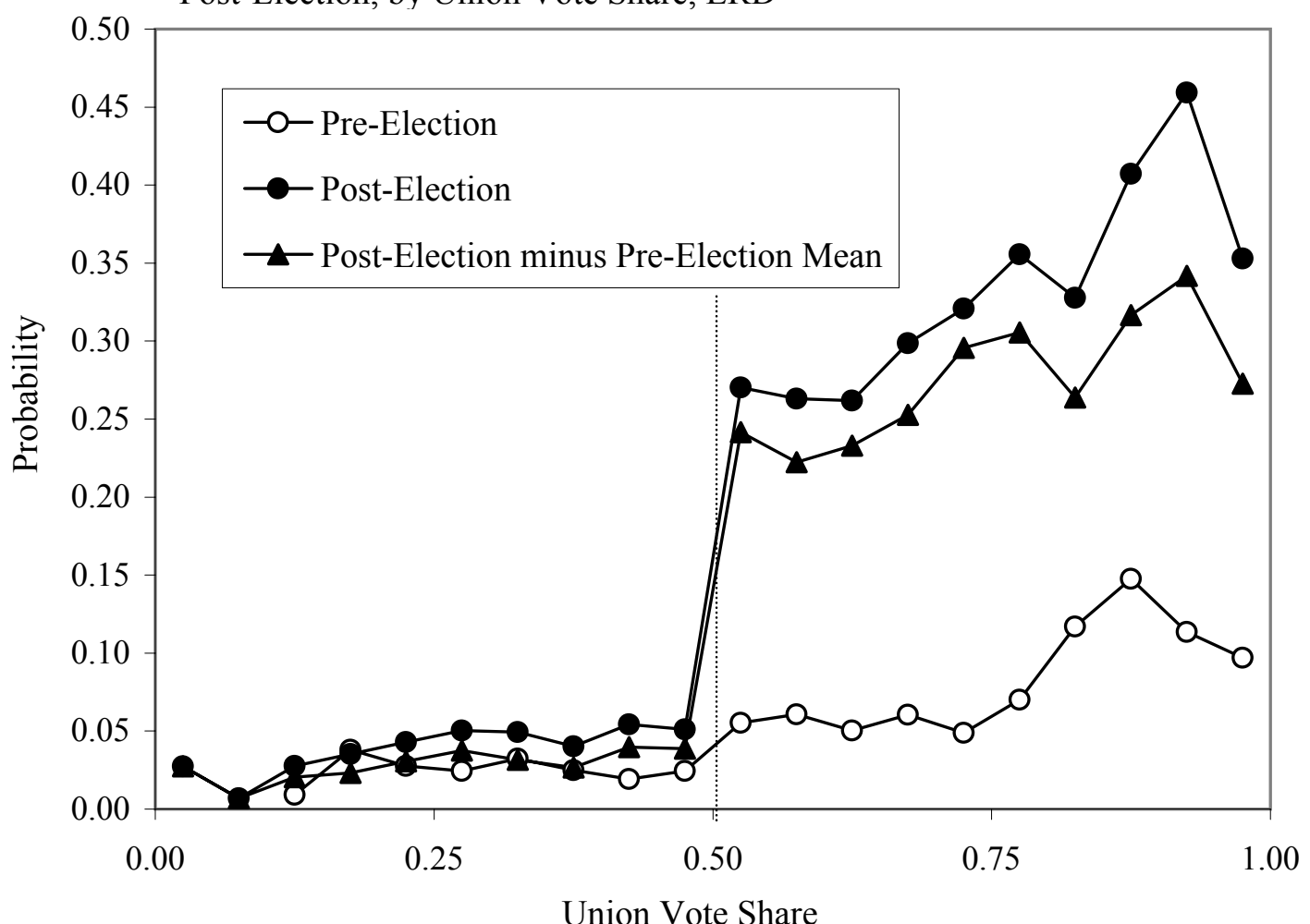

Figure VIIIb: Log(Production Hours/1000), Pre- and Post-Election, by Union Vote Share, LRD

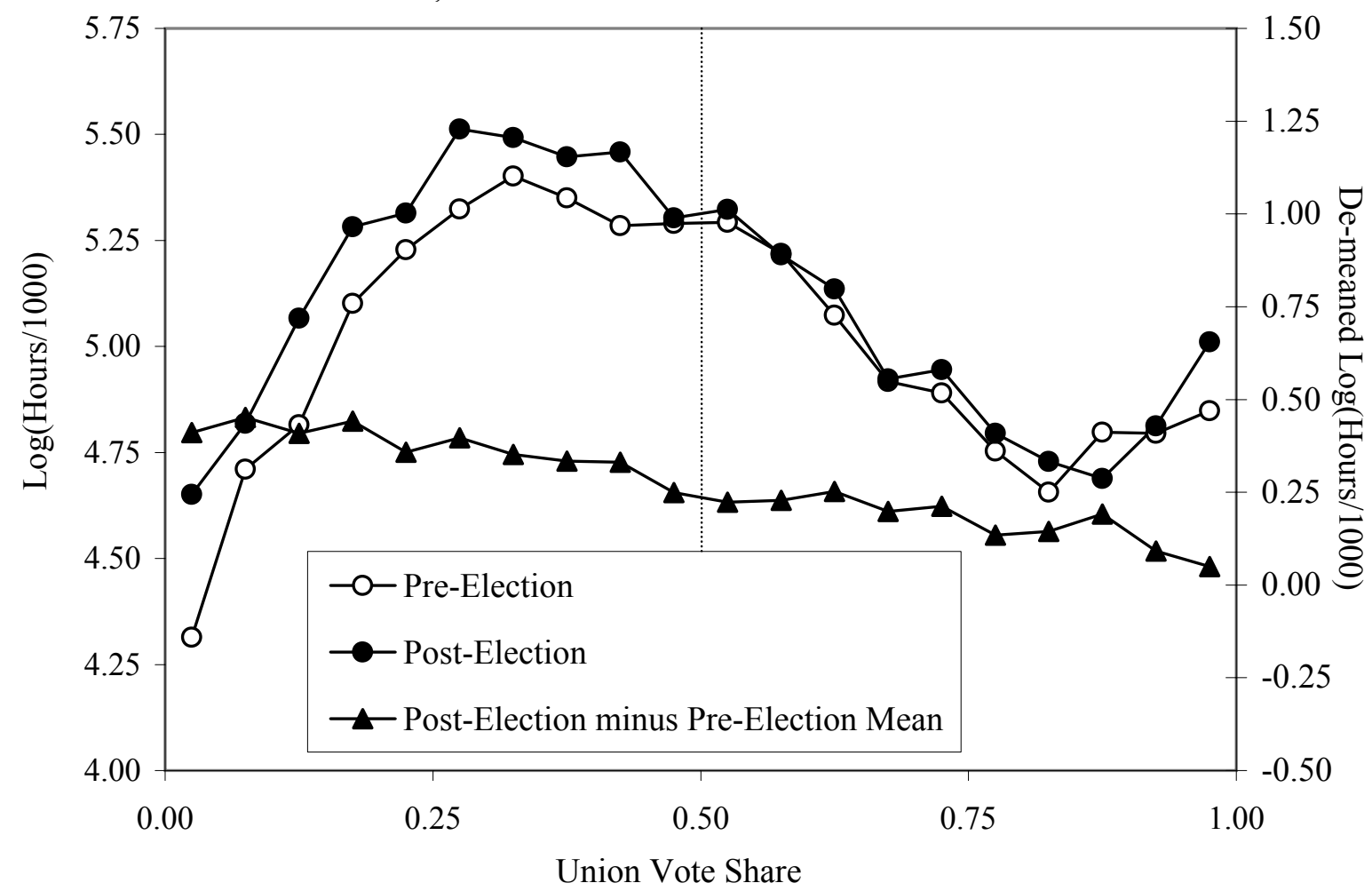

Note: Observations: Pre-Election 38870, Post-Election 28929, Post-Election minus Pre-Election Mean 28790 
Figure IXa: $\log ($ Output/1000), Pre- and Post-Election, by Union Vote

Share, LRD

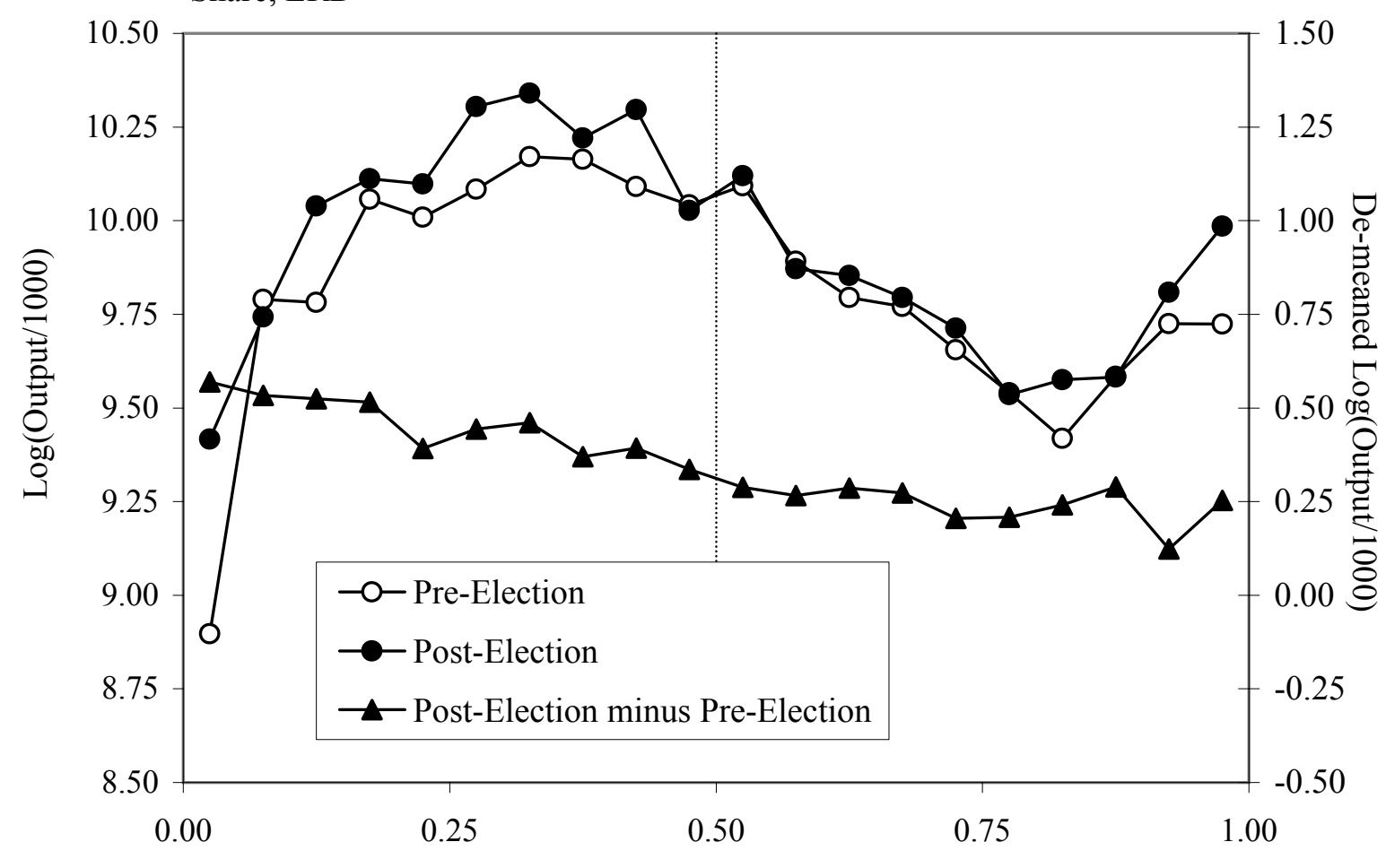

Union Vote Share

Figure IXb: $\log ($ Output/Hour), Pre- and Post-Election, by Union Vote Share, LRD

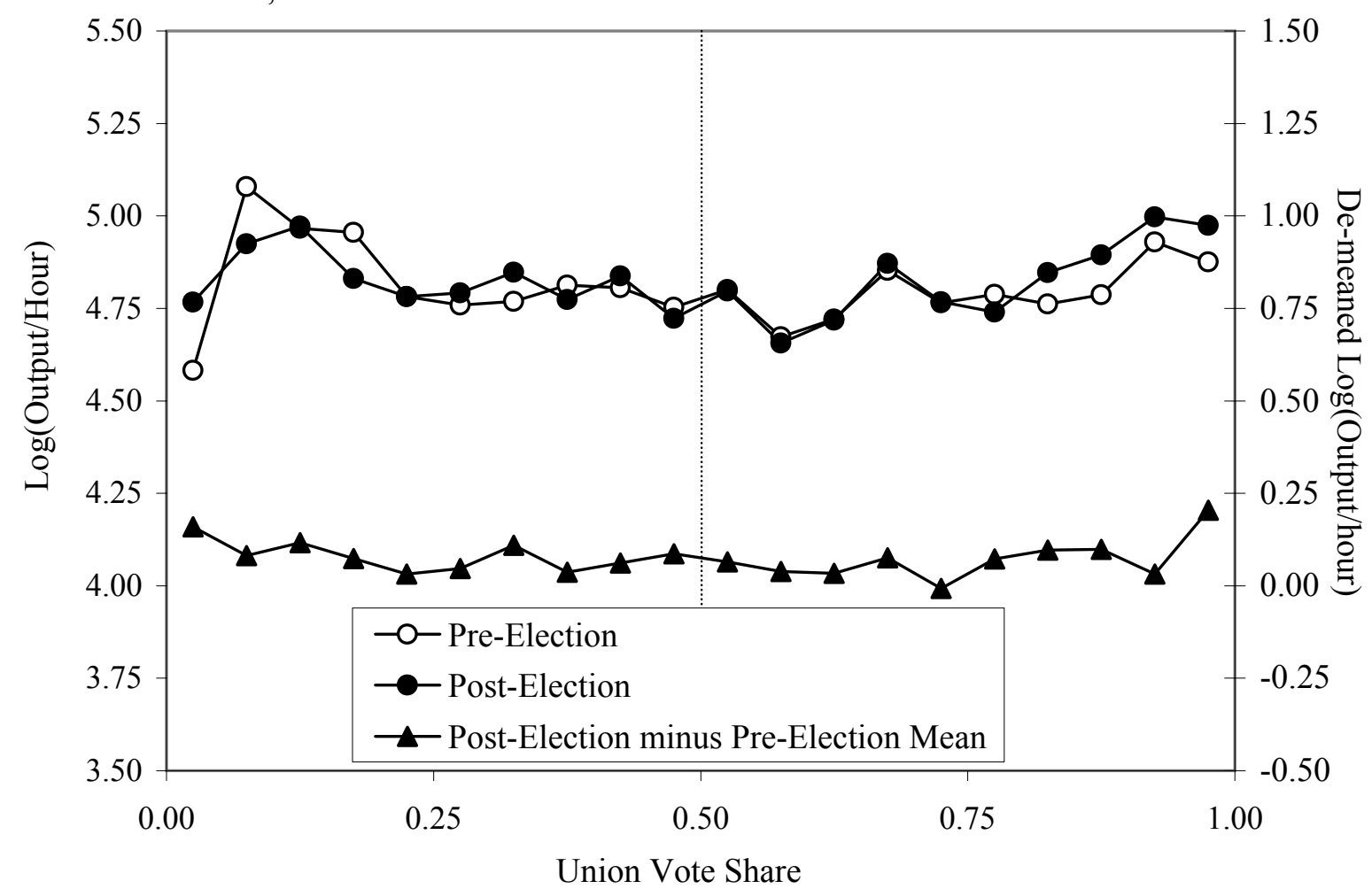

Note: Observations: Pre-Election 38854, Post-Election 28918, Post-Election minus Pre-Election Mean 28785 
Figure Xa: $\log (($ Assets/worker $) / 1000)$, Pre- and Post-Election, by Union Vote Share, LRD

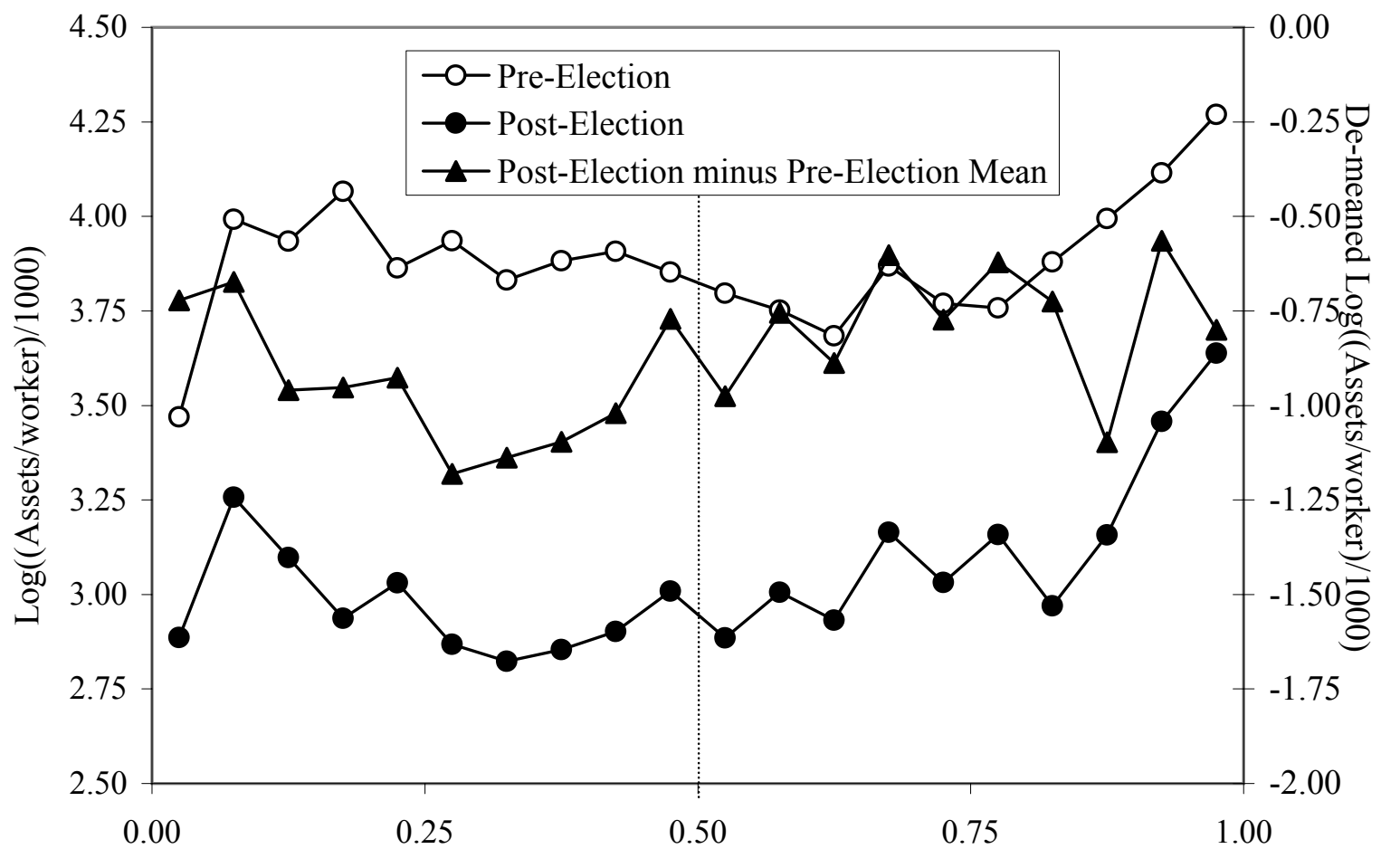

Union Vote Share

Figure Xb: Log(Production Hourly Wage), Pre- and Post-Election, by Union Vote Share, LRD

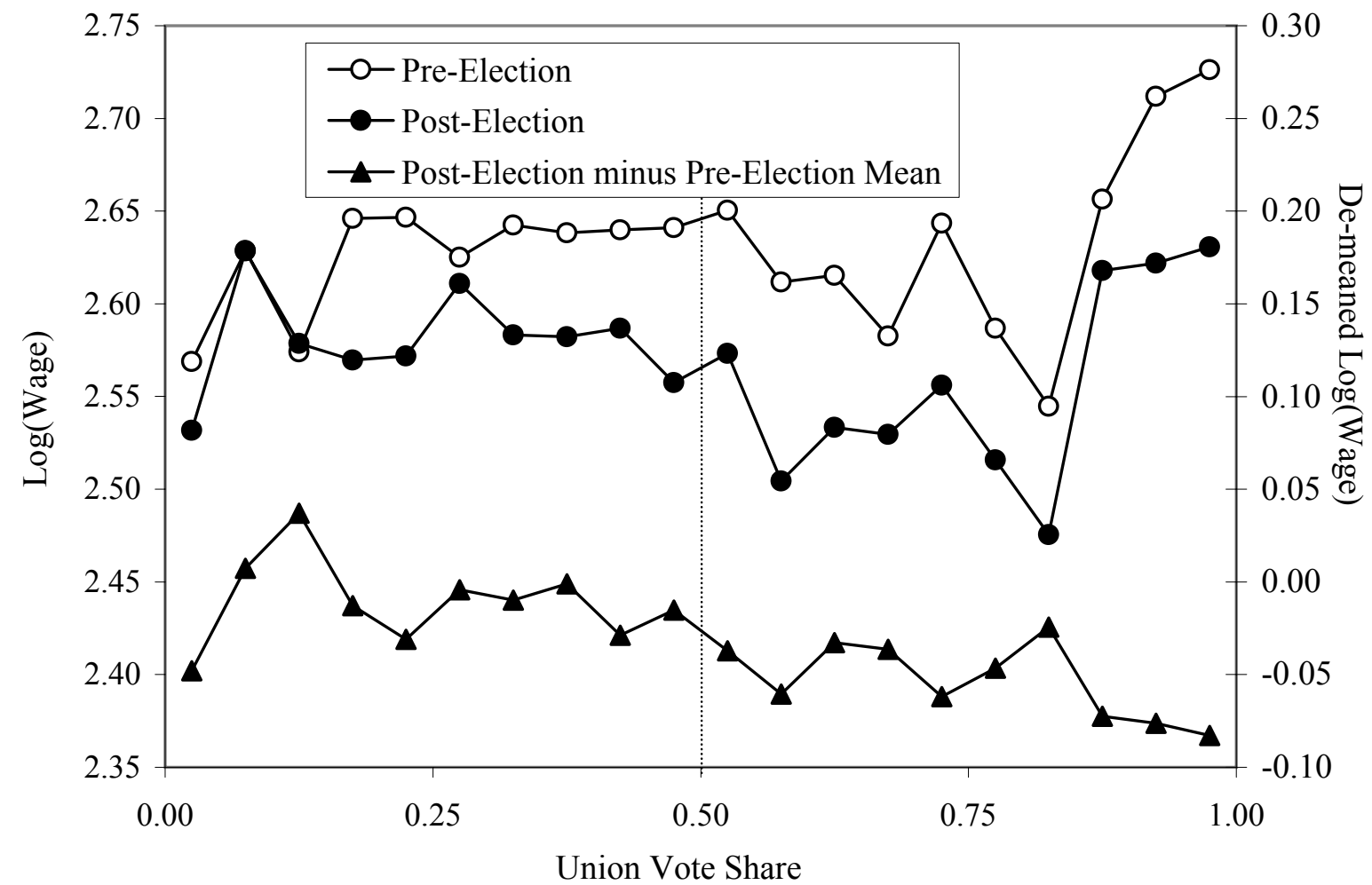

Note: Observations: Panel A, Pre-Election 37005, Post-Election 20505, Post-Election minus Pre-Election Mean 20346 Panel B, Pre-Election 38870, Post-Election 28929, Post-Election minus Pre-Election Mean 28790 
Figure XIa: Event Study Estimates of Election Impact on Log(Wage), All

Union Losses

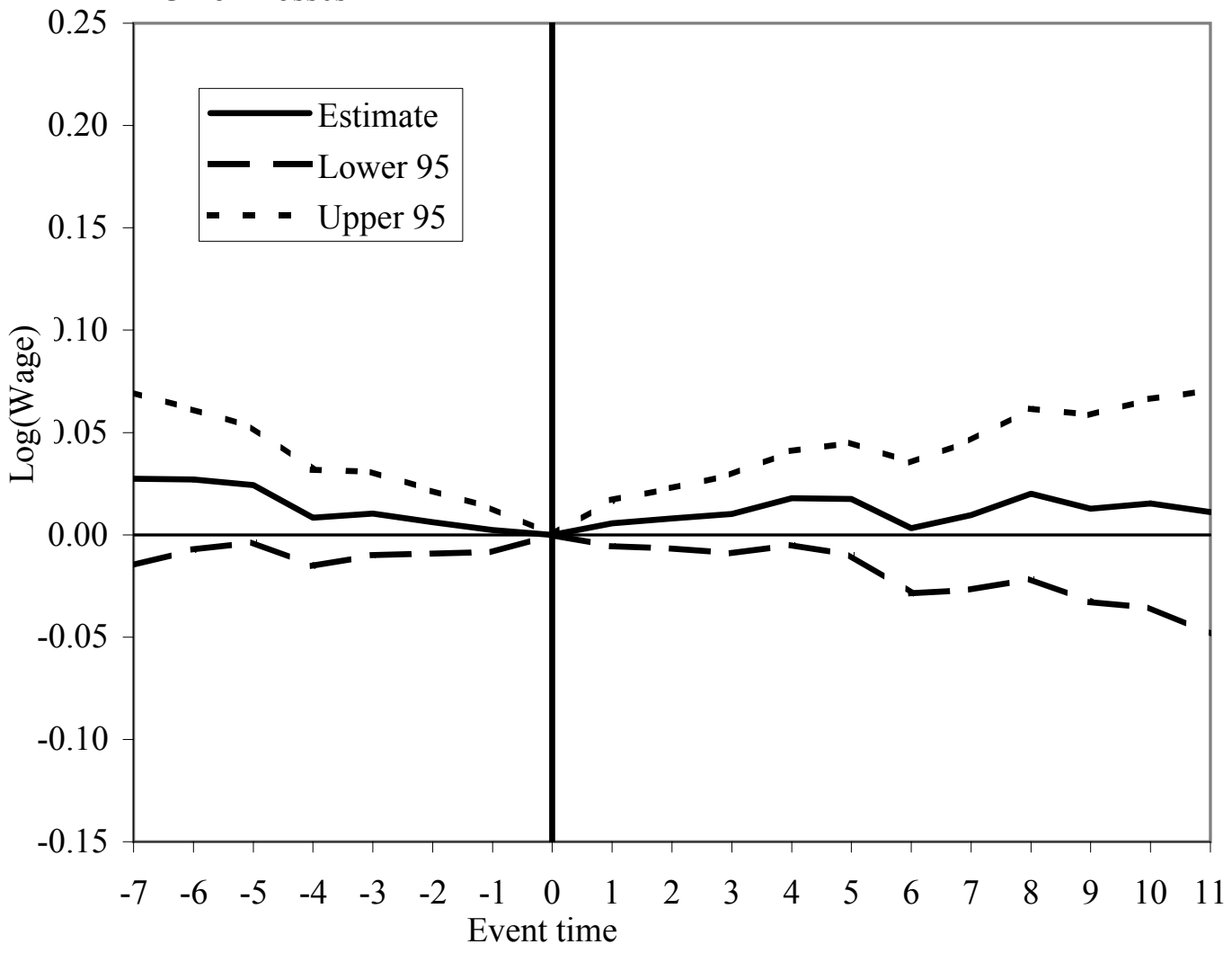

Figure XIb: Event Study Estimates of Election Impact on Log(Wage),

Union Loses, Vote Share: 30 to 50 percent

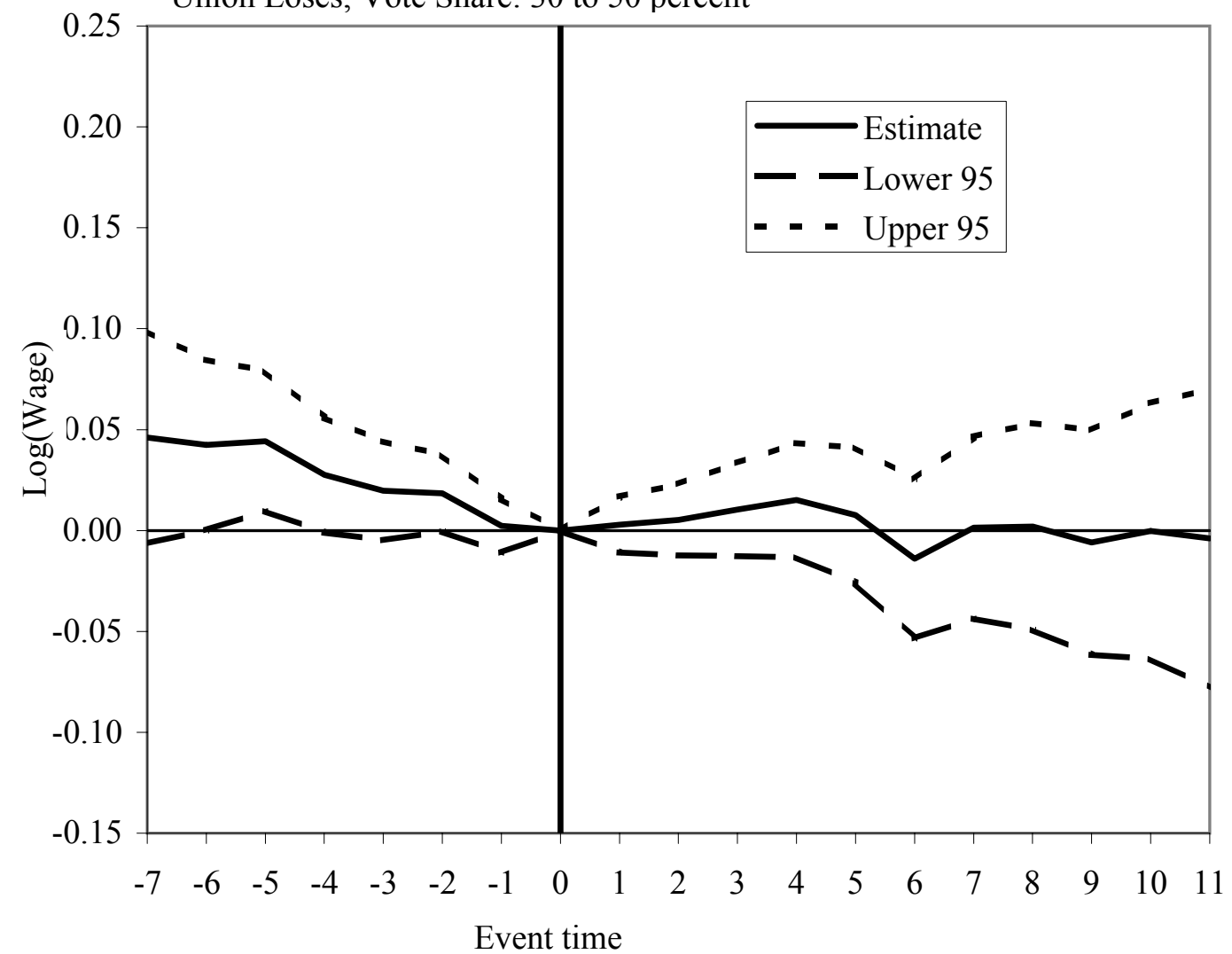

Note: Panel A, 32538 Obs, 3584 Establishments; Panel B, 14899 Obs, 1891 Establishments 


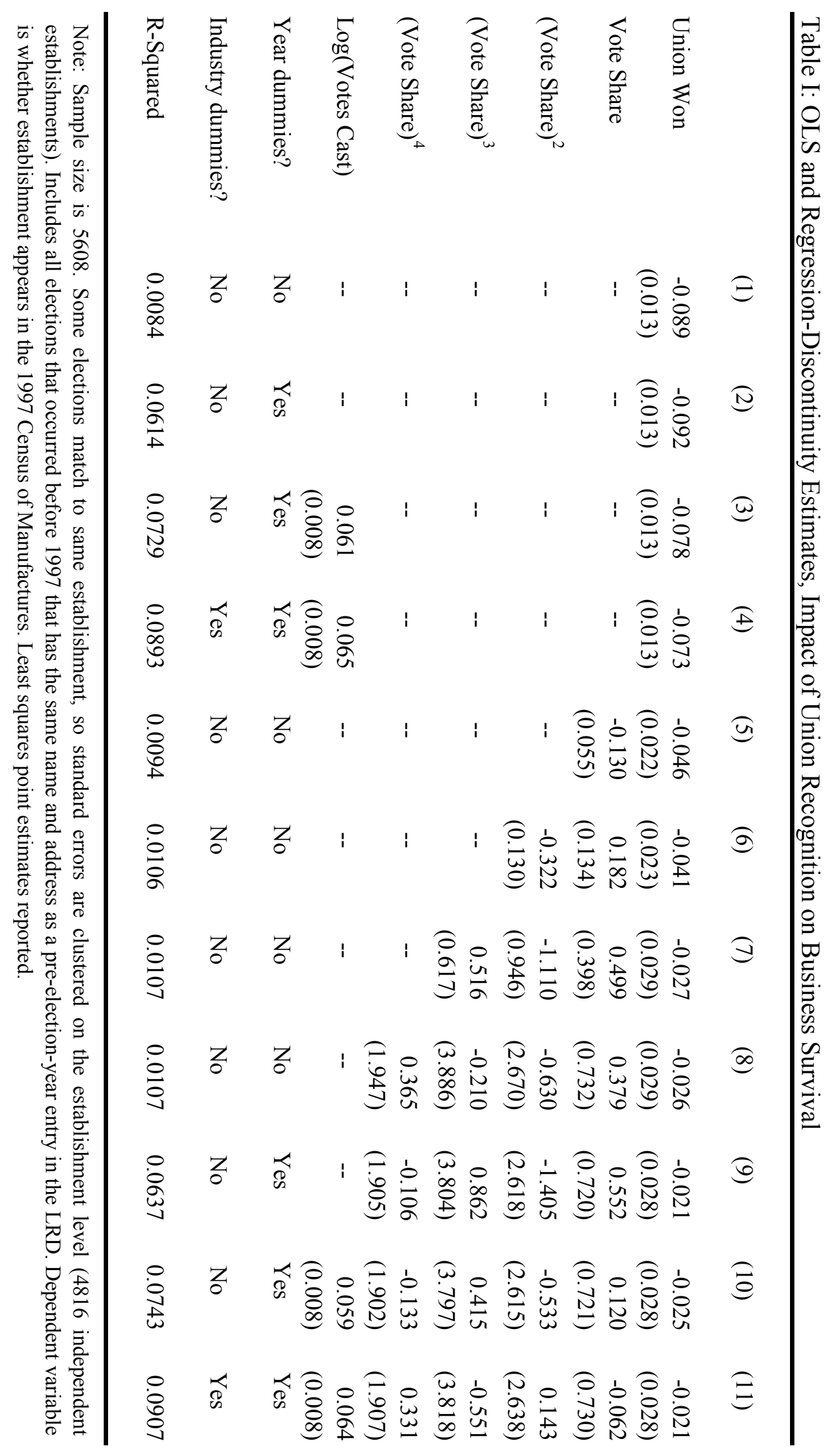




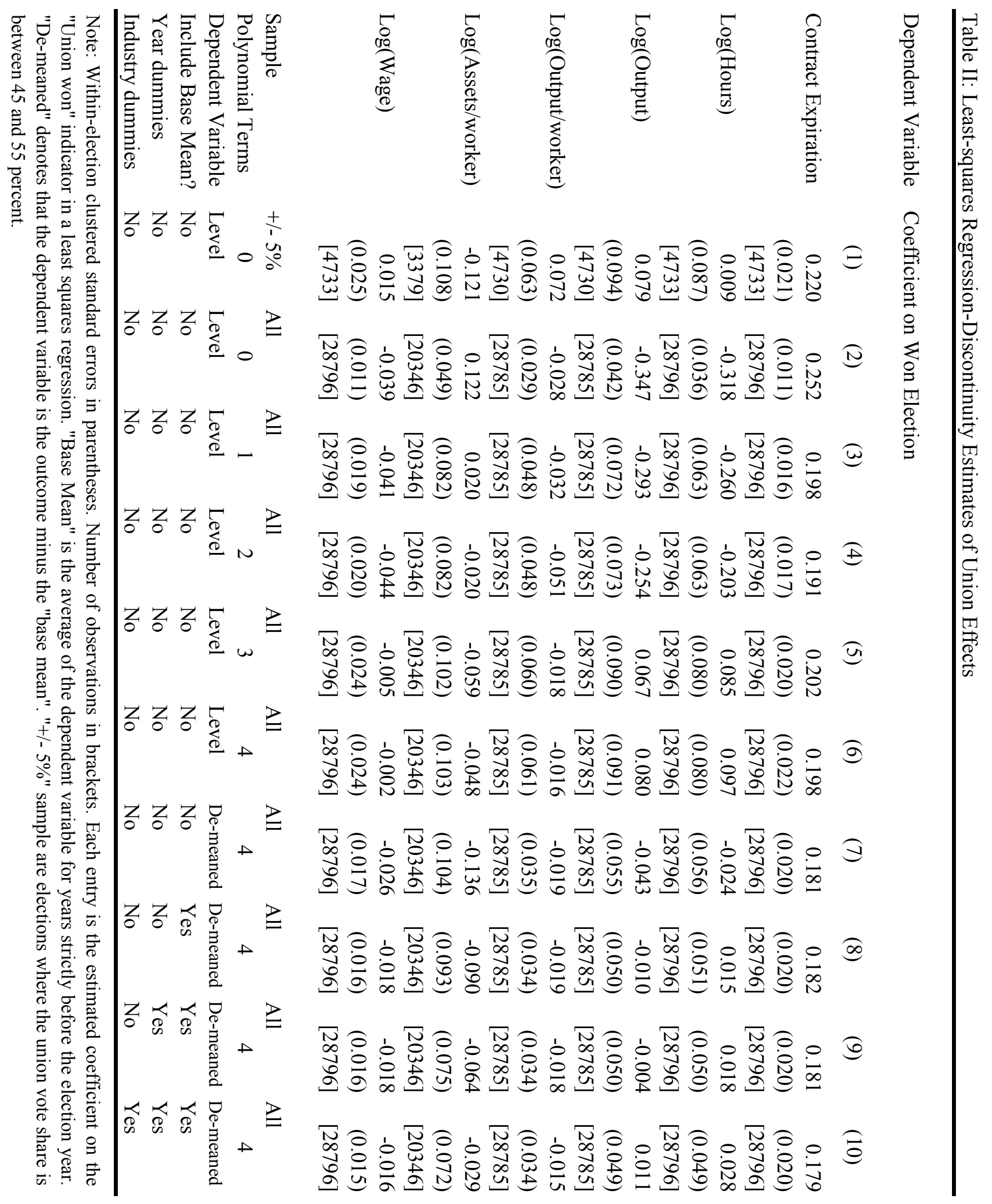


Table III: Least-squares Regression-Discontinuity Estimates of Union Effects, by Time after Election

Dependent Variable

(1)

(2)

(3)

$\begin{array}{lrrr}\text { Contract Expiration } & 0.077 & 0.307 & 0.214 \\ & (0.018) & (0.032) & (0.041) \\ & {[13240]} & {[8745]} & {[6811]} \\ \log (\text { Hours }) & 0.030 & 0.032 & 0.041 \\ & (0.042) & (0.066) & (0.094) \\ & {[13240]} & {[8745]} & {[6811]} \\ \log (\text { Output }) & 0.001 & 0.030 & 0.040 \\ & (0.044) & (0.064) & (0.092) \\ & {[13235]} & {[8742]} & {[6808]} \\ \log (\text { Output/worker }) & -0.027 & -0.004 & 0.008 \\ & (0.031) & (0.046) & (0.061) \\ & {[13235]} & {[8742]} & {[6808]} \\ \log (\text { Assets/worker }) & -0.043 & -0.035 & 0.029 \\ & (0.070) & (0.114) & (0.133) \\ \log (\text { Wage }) & {[10332]} & {[6167]} & {[3847]} \\ & -0.013 & -0.025 & -0.005 \\ & (0.015) & (0.021) & (0.028) \\ & {[13240]} & {[8745]} & {[6811]}\end{array}$

Sample

$$
\begin{array}{lll}
\text { 0-3 Years } & \text { 4-7 Years } & \text { 8+ Years } \\
\text { post-El. } & \text { post-El. } & \text { post-El. }
\end{array}
$$

Note: Within-election clustered standard errors in parentheses. Number of observations in brackets. Each entry is the estimated coefficient on the "Union won" indicator in a least squares regression. Specification is the same as Col. (10) in Table 2. Each column restricts the sample to the observations that are within the first three years, between four to seven years, and eight years or later, relative to the election year. 


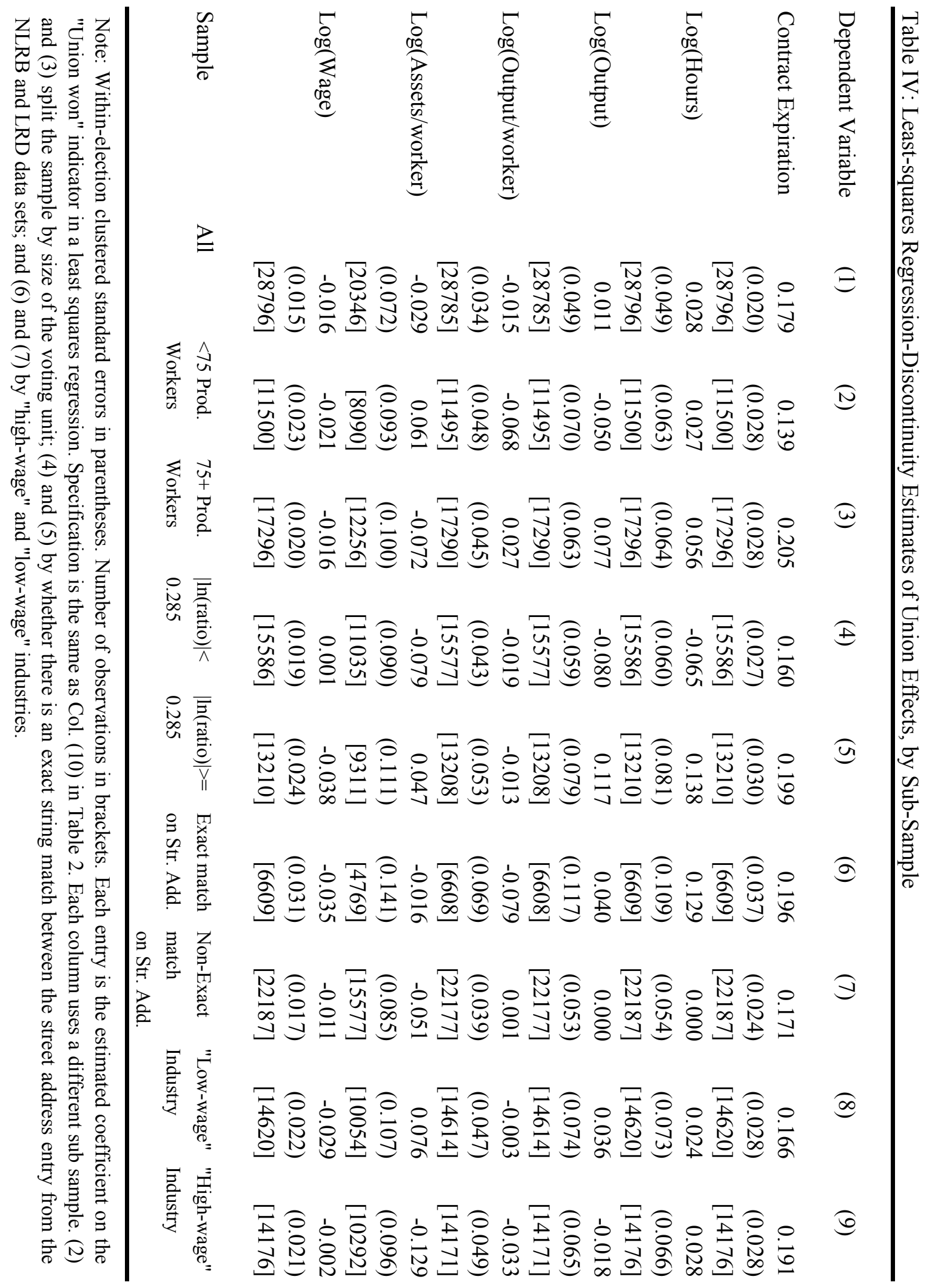


Data Set

NLRB

FMCS

InfoUSA

LRD
Description

National Labor Relations Board Election Database: Contains universe of representation elections (certification and decertification) that occurred in the U.S. between 1984 and 1999. Total observations: 62415 .

Federal Mediation and Conciliation Service Database: Contains all contract expiration notices filed with the FMCS between 1984 and 2001. Total Observations: 563565.

\section{Main Variables}

Date of election, \# eligible voters, \# votes cast, \# votes for the union

Date of Contract Expiration

InfoUSA Database: Contains all business establishments that appear in Phone Directories, Employment, Sales Volume as of May, 2001.

Longitudinal Research Database: Comprised of two components. 1) Census of Manufactures (1977, 1982, 1987, 1992, 1997): Universe of all manufacturing

Wages, Hours, Output, Total establishments in the U.S., and 2) Annual Survey of Manufactures (1974-1999): Universe

of all large manufacturing establishments plus probability sample of smaller manufacturers.

NLRB/FMCS/InfoUSA Total number of elections (62415). 20+ votes cast (33503), <1000 votes cast (33382), certification and de-certification elections only (32855), valid election date (32712).

Variables from NLRB Company name and establishment street address used to match to FMCS and InfoUSA FMCS, and InfoUSA data. 13062 of the 32712 were found in the InfoUSA database (as of May, 2001).

NLRB/FMCS/LRD

Company name and establishment street address used to match NLRB/FMCS data (32712 observations) (see above) to LRD. Kept only matches where the year from the LRD is strictly less than the year of the election. With multiple matches, single "best" match was kept. 8533 of the 32712 matched. Kept cases where the ratio of eligible voters (NLRB) to production workers (LRD) is at least half (7743 of 8533). 
Appendix Table II: Sample Means, Infousa/NLRB/FMCS and LRD/NLRB/FMCS data sets

Variable

Union Wins Election

Number of Votes Cast

Log(Votes Cast)

Total Employment

$\log ($ Employment $)$

Total Value of Shipments $(\$ 1000)$

Log(Total Value of Shipments)

Log(Shipments/Employment)

Number of Production Workers

Log(Production Workers)

Production Man-hours (1000s)

Log(Production Hours)

Shipments per Production Hour

Log(Shipments/Hour)

Employee Annual Earnings (\$1000)

Production Wage

Log(Production Wage)
Log(Annual Earnings)

\section{InfoUSA/NLRB/FMCS}

Obs Mean Std. Dev Std. Error

$\begin{array}{rrrr}27560 & 0.429 & 0.495 & (0.003) \\ 27560 & 88.6 & 107.6 & (0.6) \\ 27560 & 4.091 & 0.806 & (0.005) \\ 16987 & 172.8 & 353.0 & (2.7) \\ 16987 & 4.057 & 1.645 & (0.013) \\ 16200 & 32192.3 & 72308.4 & (568.1) \\ 16200 & 8.984 & 1.832 & (0.014) \\ 8634 & 5.111 & 0.966 & (0.010)\end{array}$

-- $\quad$--- $\quad---\quad---$

$\begin{array}{llll}-- & -- & -- & --\end{array}$

$\begin{array}{llll}-- & --- & -- & --\end{array}$

$\begin{array}{llll}-- & -- & -- & -\end{array}$

$\begin{array}{llll}--- & -- & -- & -\end{array}$

$\begin{array}{llll}--- & -- & -- & -\end{array}$

$\begin{array}{llll}-- & -- & -- & --\end{array}$

$\begin{array}{llll}-- & -- & -- & --\end{array}$

\section{LRD/NLRB/FMCS}

Obs Mean Std. Dev Std. Error

$\begin{array}{rrrr}5608 & 0.360 & 0.480 & (0.006) \\ 5608 & 111.9 & 121.9 & (1.6) \\ 5608 & 4.327 & 0.840 & (0.011) \\ 5608 & 149.6 & 192.0 & (2.6) \\ 5608 & 4.412 & 1.197 & (0.016) \\ 5608 & 32217.9 & 71991.9 & (961.3) \\ 5605 & 9.434 & 1.478 & (0.020) \\ 5605 & 5.021 & 0.772 & (0.010) \\ 5608 & 112.1 & 151.9 & (2.0) \\ 5608 & 4.077 & 1.239 & (0.017) \\ 5608 & 228.9 & 308.8 & (4.1) \\ 5608 & 4.762 & 1.281 & (0.017) \\ 5608 & 140.9 & 207.9 & (2.8) \\ 5605 & 4.671 & 0.833 & (0.011) \\ 5608 & 27.4 & 11.1 & (0.1) \\ 5608 & 3.383 & 0.374 & (0.005) \\ 5608 & 11.9 & 6.1 & (0.1) \\ 5608 & 2.538 & 0.377 & (0.005)\end{array}$

$\begin{array}{lllll}--- & 5608 & 2.538 & 0.377 & (0.005)\end{array}$

Notes: Certification election cases only. Total Employment (I/N/F: reported; L/N/F: sum of non-production workers during quarter that contains March 12and production workers). Total Value of Shipments (I/N/F and L/N/F): dollar value of products and services sold. Production workers: average of production workers in 4 quarters containing the 12th of March, May, August, and November. Production Man-Hours: sum of 4 quarters of plant man-hours of production workers. Employee Annual Earnings: Sum of earnings paid to production and non-production workers, divided by total employment. Production Wage: Earnings paid to production workers, divided by production man-hours. Dollar amounts are in 2001 dollars for InfoUSA/NLRB/FMCS, and are (CPI-adjusted) 2000 dollars for LRD/NLRB/FMCS. 
Appendix Table III: Correlation Between Similar Measures across Datasets

\begin{tabular}{|c|c|c|c|c|c|}
\hline \multirow[t]{3}{*}{ Data Set } & \multirow[t]{3}{*}{ Dependent Variable } & \multirow[t]{3}{*}{ Mean } & \multicolumn{3}{|c|}{ Slope Coefficient on Alternative Measure } \\
\hline & & & All & Exact Street & Non-Exact \\
\hline & & & & Match & Match \\
\hline \multirow[t]{3}{*}{ InfoUSA } & Log(Employment) & 4.298 & 0.913 & 0.910 & 0.906 \\
\hline & & $(0.024)$ & $(0.011)$ & $(0.017)$ & $(0.020)$ \\
\hline & & [4181] & [4181] & [2692] & [1489] \\
\hline \multirow[t]{3}{*}{ NLRB } & Log(Eligible Voters) & 4.273 & 0.237 & 0.233 & 0.248 \\
\hline & & $(0.013)$ & $(0.010)$ & $(0.013)$ & $(0.015)$ \\
\hline & & [4181] & [4181] & [2692] & [1489] \\
\hline \multirow[t]{3}{*}{ LRD } & Log(Prod. Workers) & 4.605 & 0.972 & 0.959 & 0.976 \\
\hline & & $(0.016)$ & $(0.010)$ & $(0.017)$ & $(0.012)$ \\
\hline & & [3583] & [3583] & [841] & [2742] \\
\hline \multirow[t]{3}{*}{ NLRB } & Log(Eligible Voters) & 4.678 & 0.743 & 0.824 & 0.722 \\
\hline & & $(0.014)$ & $(0.008)$ & $(0.015)$ & $(0.009)$ \\
\hline & & [3583] & [3583] & [841] & [2742] \\
\hline
\end{tabular}

Note: Standard errors in parentheses. Number of observations in brackets. Upper panel reports median regression slope coefficients. Lower panel reports OLS slope coefficients. Each entry is slope coefficient on the alternative measure (e.g. 0.913 is the slope coefficient from a median regression of Log(Employment) from InfoUSA on $\log$ (Eligible Voters) from NLRB. The entry below is the reverse median regression). "Exact Street Match" indicates that the street address matched exactly between the two data sets. 
Appendix Table IV: Coefficients on Won Election, Alternative Measures of Employer Outcomes

\begin{tabular}{|c|c|c|c|}
\hline "Labor Inputs" & & "Capital" & \\
\hline \multirow[t]{3}{*}{ Log(Total Empl.) } & 0.039 & Log(Total Assets) & -0.012 \\
\hline & $(0.045)$ & & $(0.077)$ \\
\hline & [28796] & & [20346] \\
\hline \multirow[t]{3}{*}{ Log(Non-prod. Empl.', } & 0.027 & Log(Assets/Total & -0.028 \\
\hline & $(0.051)$ & Empl.) & $(0.069)$ \\
\hline & [28096] & & {$[20346]$} \\
\hline \multirow[t]{3}{*}{ Log(Production Empl.), } & 0.037 & Log(Assets/Productior & -0.029 \\
\hline & $(0.048)$ & Empl.) & $(0.072)$ \\
\hline & [28796] & & [20346] \\
\hline \multirow[t]{3}{*}{ Log(Production Hours) } & 0.028 & Log(Assets/Productior & -0.029 \\
\hline & $(0.049)$ & Hours) & $(0.072)$ \\
\hline & [28796] & & [20346] \\
\hline "Output" & & "Wages" & \\
\hline \multirow{3}{*}{$\begin{array}{l}\text { Log(Total Value of } \\
\text { Shipments) }\end{array}$} & 0.011 & Log(Annual Earnings') & -0.028 \\
\hline & $(0.049)$ & & $(0.015)$ \\
\hline & {$[28785]$} & & [28796] \\
\hline \multirow{5}{*}{$\begin{array}{l}\text { Log(Adjusted Valut } \\
\text { of Shipments) }\end{array}$} & 0.016 & Log(Production Annua & -0.027 \\
\hline & $(0.050)$ & Earnings) & $(0.016)$ \\
\hline & {$[28778]$} & & [28796] \\
\hline & & Log(Production Hourly & -0.016 \\
\hline & & Wage) & $(0.015)$ \\
\hline "Productivity" & & & [28796] \\
\hline \multirow[t]{3}{*}{ Log(TVS/Total Empl.) } & -0.027 & Log(Non-productior & -0.009 \\
\hline & $(0.030)$ & Annual Earnings) & $(0.024)$ \\
\hline & [28785] & & [27991] \\
\hline Log(Adj. TVS/Total & -0.024 & Log(Non-prod/Prod. & 0.010 \\
\hline \multirow[t]{2}{*}{ Empl.) } & $(0.030)$ & Annual Earnings) & $(0.028)$ \\
\hline & [28778] & & [27991] \\
\hline Log(TVS/Production & -0.026 & Log(Adjusted Annua & -0.025 \\
\hline \multirow[t]{2}{*}{ Empl.) } & $(0.033)$ & Earnings) & $(0.015)$ \\
\hline & {$[28785]$} & & [28796] \\
\hline Log(Adj. TVS/Prod. & -0.023 & Log(Adj. Productior & -0.024 \\
\hline \multirow[t]{2}{*}{ Empl.) } & $(0.034)$ & Annual Earnings) & $(0.016)$ \\
\hline & [28778] & & [28796] \\
\hline Log(TVS/Production & -0.015 & Log(Adj. Productior & -0.013 \\
\hline \multirow[t]{2}{*}{ Hours) } & $(0.034)$ & Hourly Wage) & $(0.016)$ \\
\hline & [28785] & & [28796] \\
\hline Log(Adj. TVS/Prod. & -0.012 & Log(Adj. Non-prod. & -0.006 \\
\hline \multirow[t]{2}{*}{ Hours) } & $(0.034)$ & Annual Earnings) & $(0.025)$ \\
\hline & [28778] & & [27991] \\
\hline
\end{tabular}

Note: Entries are coefficients from specification (10) from Table 2). Clustered (on establishment) standard errors in parentheses, number of observations in brackets. Adjusted TVS: TVS + net change in finished goods inventory + net change in work-in-process inventory. Adjusted wage variables add total supplementary labor costs to the payroll before dividing by employment (or hours). For production and non-production "wage" variables, total supplementary labor costs are first mulitplied by the fraction of the payroll that is paid to production or non-production workers, before added to the respective payrolls. 
Appendix Table V: OLS and Regression-Discontinuity Estimates on Business Survival, Decertifications

\begin{tabular}{|c|c|c|c|c|c|c|c|c|c|c|c|}
\hline & (1) & (2) & (3) & $(4)$ & $(5)$ & (6) & (7) & (8) & (9) & $(10)$ & (11) \\
\hline Union Won & $\begin{array}{l}-0.030 \\
(0.029)\end{array}$ & $\begin{array}{l}-0.036 \\
(0.029)\end{array}$ & $\begin{array}{l}-0.047 \\
(0.029)\end{array}$ & $\begin{array}{r}-0.035 \\
(0.029)\end{array}$ & $\begin{array}{r}-0.058 \\
(0.048)\end{array}$ & $\begin{array}{r}-0.035 \\
(0.049)\end{array}$ & $\begin{array}{r}-0.019 \\
(0.061)\end{array}$ & $\begin{array}{r}-0.027 \\
(0.062)\end{array}$ & $\begin{array}{r}-0.031 \\
(0.062)\end{array}$ & $\begin{array}{r}-0.026 \\
(0.061)\end{array}$ & $\begin{array}{r}-0.021 \\
(0.062)\end{array}$ \\
\hline Vote Share & & & & & $\begin{array}{r}0.086 \\
(0.120)\end{array}$ & $\begin{array}{r}0.536 \\
(0.266)\end{array}$ & $\begin{array}{r}0.815 \\
(0.738)\end{array}$ & $\begin{array}{r}1.590 \\
(1.332)\end{array}$ & $\begin{array}{r}1.560 \\
(1.309)\end{array}$ & $\begin{array}{r}1.847 \\
(1.307)\end{array}$ & $\begin{array}{r}1.755 \\
(1.296)\end{array}$ \\
\hline$(\text { Vote Share })^{2}$ & & & & & & $\begin{array}{r}-0.561 \\
(0.300)\end{array}$ & $\begin{array}{r}-1.338 \\
(1.911)\end{array}$ & $\begin{array}{r}-4.887 \\
(5.356)\end{array}$ & $\begin{array}{r}-5.005 \\
(5.234)\end{array}$ & $\begin{array}{r}-6.423 \\
(5.248)\end{array}$ & $\begin{array}{l}-6.040 \\
(5.239)\end{array}$ \\
\hline$(\text { Vote Share })^{3}$ & & & & & & & $\begin{array}{r}0.546 \\
(1.316)\end{array}$ & $\begin{array}{r}6.414 \\
(8.356)\end{array}$ & $\begin{array}{r}6.866 \\
(8.118)\end{array}$ & $\begin{array}{r}8.949 \\
(8.169)\end{array}$ & $\begin{array}{r}8.440 \\
(8.196)\end{array}$ \\
\hline$(\text { Vote Share })^{4}$ & & & & & & & & $\begin{array}{r}-3.138 \\
(4.414)\end{array}$ & $\begin{array}{r}-3.495 \\
(4.269)\end{array}$ & $\begin{array}{r}-4.465 \\
(4.304)\end{array}$ & $\begin{array}{c}-4.228 \\
(4.338)\end{array}$ \\
\hline Log(Votes Cast) & & & $\begin{array}{r}0.053 \\
(0.017)\end{array}$ & $\begin{array}{r}0.050 \\
(0.018)\end{array}$ & & & & & & $\begin{array}{r}0.052 \\
(0.017)\end{array}$ & $\begin{array}{r}0.049 \\
(0.018)\end{array}$ \\
\hline Year dummies? & No & Yes & Yes & Yes & No & No & No & No & Yes & Yes & Yes \\
\hline Industry dummies? & No & No & No & Yes & No & No & No & No & No & No & Yes \\
\hline R-Squared & 0.001 & 0.0394 & 0.048 & 0.0684 & 0.0015 & 0.0051 & 0.0053 & 0.0058 & 0.0442 & 0.0523 & 0.0723 \\
\hline
\end{tabular}

Note: Sample size is 1085. Some elections match to same establishment, so standard errors are clustered on the establishment level (998 independent establishments). Includes all elections that occurred before 1997 that has the same name and address as a pre-election-year entry in the LRD. Dependent variable is whether establishment appears in the 1997 Census of Manufactures. Least squares point estimates reported. 
Dependent Variable Coefficient on Won Election

\begin{tabular}{|c|c|c|c|c|c|c|c|c|c|c|}
\hline & (1) & (2) & (3) & (4) & (5) & (6) & (7) & (8) & (9) & (10) \\
\hline \multirow[t]{3}{*}{ Contract Expiration } & 0.257 & 0.328 & 0.280 & 0.261 & 0.242 & 0.226 & 0.217 & 0.220 & 0.218 & 0.232 \\
\hline & $(0.060)$ & $(0.026)$ & $(0.042)$ & $(0.045)$ & $(0.056)$ & $(0.058)$ & $(0.056)$ & $(0.055)$ & $(0.056)$ & $(0.054)$ \\
\hline & [1098] & [5954] & [5954] & [5954] & [5954] & [5954] & [5954] & [5954] & [5954] & [5954] \\
\hline \multirow[t]{3}{*}{ Log(Hours) } & -0.071 & 0.016 & 0.002 & -0.005 & -0.021 & -0.038 & 0.006 & -0.006 & -0.004 & -0.005 \\
\hline & $(0.054)$ & $(0.024)$ & $(0.038)$ & $(0.039)$ & $(0.049)$ & $(0.050)$ & $(0.037)$ & $(0.035)$ & $(0.035)$ & $(0.031)$ \\
\hline & [1098] & [5954] & [5954] & [5954] & [5954] & {$[5954]$} & [5954] & [5954] & [5954] & [5954] \\
\hline \multirow[t]{3}{*}{ Log(Output) } & -0.243 & 0.088 & -0.115 & -0.104 & -0.414 & -0.381 & -0.160 & -0.193 & -0.196 & -0.205 \\
\hline & $(0.190)$ & $(0.081)$ & $(0.142)$ & $(0.143)$ & $(0.176)$ & $(0.174)$ & $(0.105)$ & $(0.100)$ & $(0.099)$ & $(0.094)$ \\
\hline & [1098] & [5954] & [5954] & [5954] & [5954] & {$[5954]$} & [5954] & {$[5954]$} & [5954] & [5954] \\
\hline \multirow{3}{*}{ Log(Output/worker) } & -0.233 & 0.153 & -0.014 & 0.002 & -0.484 & -0.473 & -0.221 & -0.249 & -0.252 & -0.236 \\
\hline & $(0.184)$ & $(0.088)$ & $(0.153)$ & $(0.150)$ & $(0.186)$ & $(0.183)$ & $(0.096)$ & $(0.092)$ & $(0.090)$ & $(0.087)$ \\
\hline & [1098] & [5951] & {$[5951]$} & [5951] & [5951] & {$[5951]$} & [5951] & {$[5951]$} & [5951] & [5951] \\
\hline \multirow[t]{3}{*}{ Log(Assets/worker) } & 0.011 & 0.065 & 0.101 & 0.106 & -0.070 & -0.092 & -0.065 & -0.067 & -0.067 & -0.043 \\
\hline & $(0.153)$ & $(0.065)$ & $(0.110)$ & $(0.111)$ & $(0.144)$ & $(0.142)$ & $(0.063)$ & $(0.063)$ & $(0.063)$ & $(0.062)$ \\
\hline & [1098] & [5951] & [5951] & [5951] & [5951] & [5951] & [5951] & [5951] & [5951] & [5951] \\
\hline \multirow[t]{3}{*}{ Log(Wage) } & -0.342 & -0.048 & 0.077 & 0.015 & -0.128 & -0.132 & -0.156 & -0.146 & 0.001 & -0.033 \\
\hline & $(0.226)$ & $(0.098)$ & $(0.163)$ & $(0.162)$ & $(0.207)$ & $(0.207)$ & $(0.189)$ & $(0.176)$ & $(0.141)$ & $(0.128)$ \\
\hline & [770] & [4205] & [4205] & [4205] & [4205] & [4205] & [4205] & [4205] & [4205] & [4205] \\
\hline Sample & $+/-5 \%$ & All & All & All & All & All & All & All & All & All \\
\hline Polynomial Terms & 0 & 0 & 1 & 2 & 3 & 4 & 4 & 4 & 4 & 4 \\
\hline Dependent Variable & Level & Level & Level & Level & Level & Level & De-meaned & De-meaned & De-meaned & De-meaned \\
\hline Include Base Mean? & No & No & No & No & No & No & No & Yes & Yes & Yes \\
\hline Year dummies & No & No & No & No & No & No & No & No & Yes & Yes \\
\hline Industry dummies & No & No & No & No & No & No & No & No & No & Yes \\
\hline
\end{tabular}

Note: Within-election clustered standard errors in parentheses. Number of observations in brackets. Each entry is the estimated coefficient on the "Union won" indicator in a least squares regression. "Base Mean" is the average of the dependent variable for years strictly before the election year. "De-meaned" denotes that the dependent variable is the outcome minus the "base mean". "+/- 5\%" sample are elections where the union vote share is between 45 and 55 percent. 
Appendix Table VII: Least-squares Regression-Discontinuity Estimates of Union Effects, Decertifications

Dependent Variable

Contract Expiration

$\log ($ Hours $)$

$\log ($ Output $)$

$\log ($ Output/worker)

$\log ($ Assets/worker)

$\log ($ Wage $)$
(1)

$\begin{array}{rrr}0.106 & 0.380 & 0.192 \\ (0.063) & (0.068) & (0.092) \\ {[2620]} & {[1839]} & {[1495]} \\ -0.026 & 0.021 & 0.018 \\ (0.032) & (0.041) & (0.067) \\ {[2620]} & {[1839]} & {[1495]} \\ -0.155 & -0.138 & -0.372 \\ (0.082) & (0.119) & (0.174) \\ {[2620]} & {[1839]} & {[1495]} \\ -0.139 & -0.193 & -0.450 \\ (0.076) & (0.112) & (0.157) \\ {[2619]} & {[1838]} & {[1494]} \\ 0.012 & -0.064 & -0.108 \\ (0.060) & (0.085) & (0.118) \\ {[2619]} & {[1838]} & {[1494]} \\ -0.091 & -0.075 & -0.037 \\ (0.133) & (0.199) & (0.211) \\ {[2071]} & {[1284]} & {[850]}\end{array}$

(3)

(2)

192

372

$-0.450$
(850]

\begin{tabular}{llll} 
Sample & $\begin{array}{l}\text { 0-3 Years } \\
\text { post-El. }\end{array}$ & $\begin{array}{l}\text { 4-7 Years } \\
\text { post-El. }\end{array}$ & $\begin{array}{l}\text { 8+ Years } \\
\text { post-El. }\end{array}$ \\
\hline
\end{tabular}

Note: Within-election clustered standard errors in parentheses. Number of observations in brackets. Each entry is the estimated coefficient on the "Union won" indicator in a least squares regression. Specification is the same as Col. (10) in Table 2. Each column restricts the sample to the observations that are within the first three years, between four to seven years, and eight years or later, relative to the election year. 